\title{
Augmented Reality
}

\section{in Support of Intelligent Manufacturing A Systematic Literature Review}

\author{
Johannes Egger and Tariq Masood \\ University of Cambridge
}
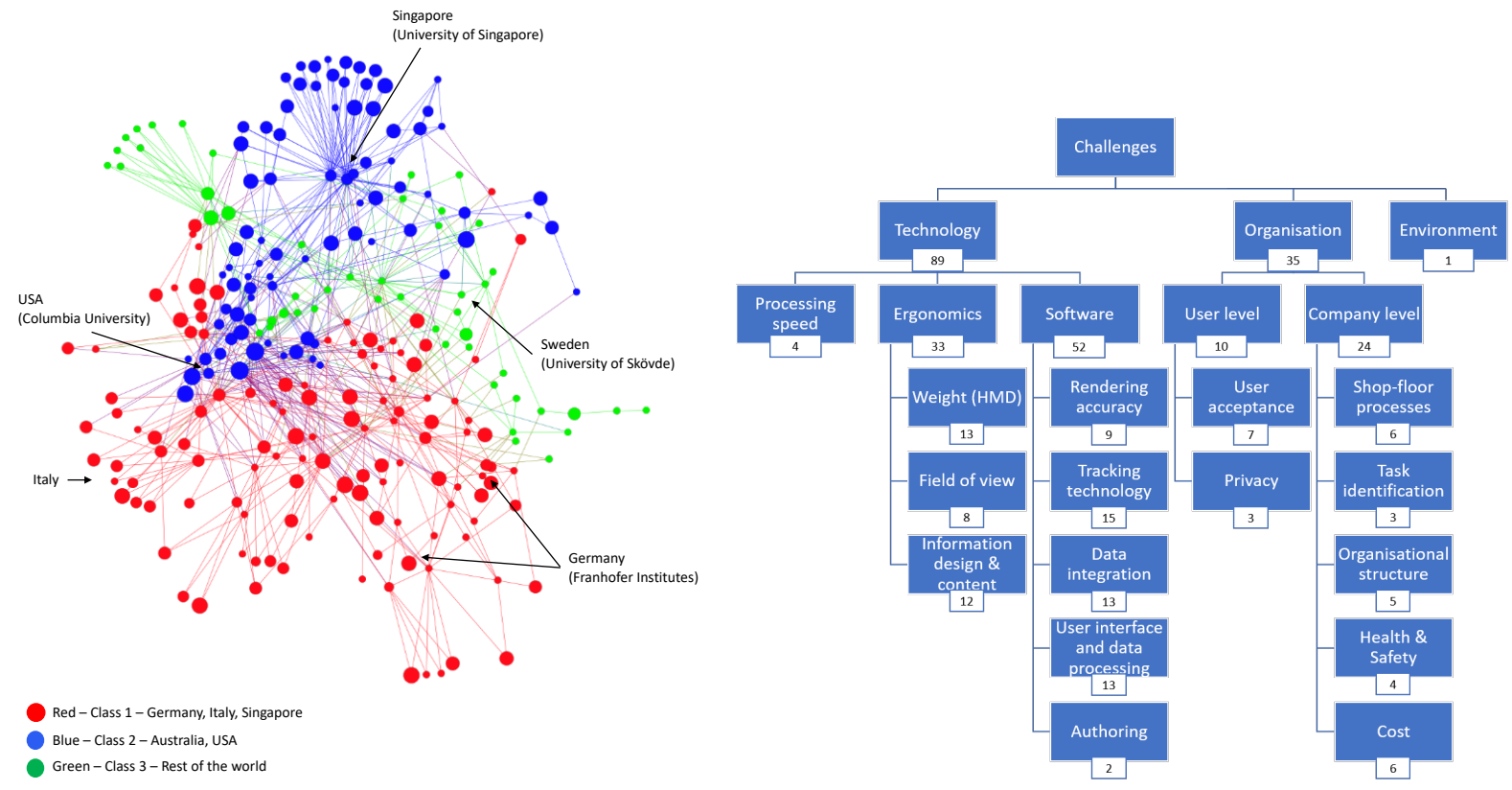

\section{Highlights}

0 Augmented Reality (AR) is a major part of industry 4.0 advancements

- While AR is not ready yet for industrial deployment in some areas, it is already used in others

- Hardware and software still require improvements in certain areas of AR

- The context of research concerning AR is getting increasingly broader as its implementation rises

$\circ \quad$ The future research needs to focus on intelligent manufacturing applications of $A R$ 


\title{
Augmented Reality in Support of Intelligent Manufacturing - A Systematic Literature Review
}

\author{
Johannes Egger ${ }^{1}$ and Tariq Masood ${ }^{1,2^{*}}$ \\ ${ }^{1}$ Institute for Manufacturing, Department of Engineering, University of Cambridge, 17 Charles Babbage Road, Cambridge \\ CB3 OFS, UK
}

${ }^{2}$ Engineering Design Centre, Department of Engineering, University of Cambridge, Trumpington Street, Cambridge, CB2 1PZ, UK

*E: tm487@cam.ac.uk

\begin{abstract}
Industry increasingly moves towards digitally enabled 'smart factories' that utilise the internet of things (IoT) to realise intelligent manufacturing concepts like predictive maintenance or extensive machine to machine communication. A core technology to facilitate human integration in such a system is augmented reality (AR), which provides people with an interface to interact with the digital world of a smart factory. While AR is not ready yet for industrial deployment in some areas, it is already used in others. To provide an overview of research activities concerning AR in certain shop floor operations, a total of 96 relevant papers from 2011 to 2018 are reviewed. This paper presents the state of the art, the current challenges, and future directions of manufacturing related AR research through a systematic literature review and a citation network analysis. The results of this review indicate that the context of research concerning AR gets increasingly broader, especially by addressing challenges when implementing AR solutions.
\end{abstract}

\section{Keywords}

Augmented Reality, AR, Intelligent Manufacturing, Systematic Literature Review, Challenges, Technology, Visualisation, Cyber-Physical Systems, Industry 4.0, Internet of Things, IoT, Smart Factory, Industrial Digitalisation 


\section{List of Abbreviations}

$\begin{array}{ll}\text { AR } & \text { Augmented Reality } \\ \text { AV } & \text { Augmented Virtuality } \\ \text { CPPS } & \text { Cyber-Physical Production System } \\ \text { DOI } & \text { Digital Object Identifier } \\ \text { HHD } & \text { Hand-Held Device } \\ \text { HMD } & \text { Head-Mounted Device } \\ \text { IOT } & \text { Internet of Things } \\ \text { MR } & \text { Mixed Reality } \\ \text { RV } & \text { Reality-Virtuality } \\ \text { SCADA } & \text { Supervisory Control and Data Acquisition } \\ \text { TAM } & \text { Technology Acceptance Model } \\ \text { TLX } & \text { Task Load Index } \\ \text { VR } & \text { Virtual Reality }\end{array}$




\section{Introduction}

Since the first industrial revolution, which introduced steam power and mechanised production, the manufacturing industry has always been subject to significant changes (Seki et al. 2013). The second industrial revolution brought assembly lines and electricity into factories. The advent of automation led to a third industrial revolution in the 1970s (Oztemel and Gursev 2018). The Industry 4.0 or similar initiatives (Li 2018) promote the incorporation of digital technologies into the manufacturing environment to enable an intelligent production system (Pacaux-Lemoine et al. 2017), powering a fourth industrial revolution (see Fig 1).

Digital technologies are central to realisation of intelligence in the manufacturing industry of the future. Examples of digital technologies include but are not limited to AR (Masood and Egger 2019; Masood and Egger In press), virtual reality (Malik et al. In press), predictive maintenance (Yan et al. 2017), cloud computing (Zhang et al. 2017), loT (Xu et al. 2014), big data (Xu and Duan 2018; Belhadi et al. 2019) and digital twins (Malik et al. In press). Through adoption of digital technologies, data gathering and information creation reaches unprecedented levels. The vision of Industry 4.0 is to build cyber-physical production systems (CPPS) which connect the physical and the digital world seamlessly to make manufacturing increasingly intelligent, thus, to increase (autonomous) adaptability, autonomy, and flexibility (Smith et al. 2013; Serrano and Fischer 2007). Despite this focus on technology, humans still play an important role in manufacturing operations (Kagermann et al. 2013; Longo et al. 2017; Peruzzini et al. In press; Segura et al. In press).

AR comes into play to make vast amounts of data created by CPPS contextually accessible in real time for humans (Yao et al. 2017). Hence, AR is central to enabling this human centred Industry 4.0 manufacturing approach (Cheng et al. 2018; Kong et al. 2018) by supporting humans within an intelligent manufacturing environment. AR is classified by the European Union as one of the main technologies that will drive the development of smart factories (Davies 2015). In order to facilitate collaboration and interaction between humans and production systems based on digital data, researchers focus on AR to achieve that goal (Oztemel and Gursev 2018).

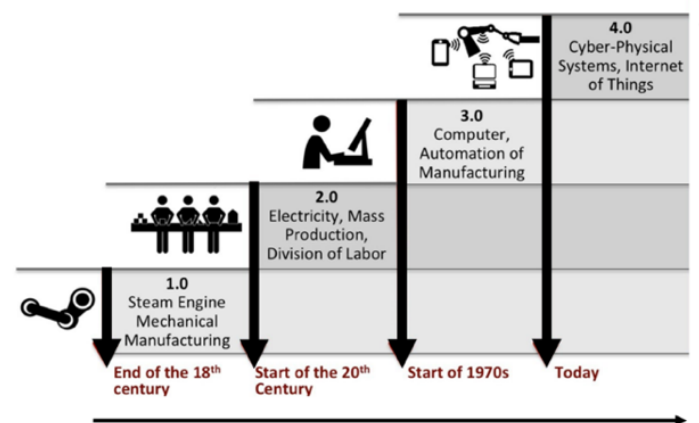

While a lot of technologies play their part in the fourth industrial revolution (Davies 2015), AR is the only of those technologies focusing on improving the interaction between humans and machines and, thus, between humans and intelligent manufacturing systems. Hence, it is crucial to understand the current state of research concerned with AR in manufacturing.

The most recent literature review article focusing on AR in the manufacturing industry was published in 2012 (Nee et al. 2012). However, that review was not systematic. In general, most of the reviews are not conducted rigorously through a systematic review. One exception to that focuses only on maintenance operations (Palmarini et al. 2018). Similarly, Fraga-Lamas et al. (2018) only focussed on shipbuilding. Nee and Ong (2013) and Nee et al. (2012) showed a broad range of applications in industry; especially the manufacturing industry. However, the broader context of current challenges or future research directions, for example, the organisational challenges, are not considered in those studies. Table 1 shows the gaps in other relevant reviews which this paper aims to fill.

This paper examines the present research status and challenges connected to AR in support of (intelligent) manufacturing applications. The focus of this paper is broader than a particular manufacturing sector, or a particular manufacturing related task, e.g. maintenance. Based on the reviewed studies, challenges and future research directions are identified. Here, not only technological issues are analysed but the broader organisational contexts of current challenges are also taken into account. To do so, a systematic literature review was conducted. The rigorous methodology ensured the repeatability of the study. While having a similar methodology as Palmarini et al. (2018), this review paper does not only focus on maintenance operations.

The rest of the paper is organised as follows. After providing a background to AR, the methodology applied in this review paper is described. The next section elaborates on the current status of research. Then, the current challenges hindering the adoption of $A R$ in manufacturing are discussed. Based on those challenges, future research directions are explored.

Increasing intelligence of manufacturing systems

Decentrally connected cyber physical systems

Intelligence: Adaptability, autonomy, and flexibility through decentralised decision making; Increased data generation and processing Automation and improved coordination.

Intelligence: Logic based automation; Automated, but inflexible production systems; Centrally connected manufacturing systems

Mass production through highest specialisation in manual labour. No intelligence: Division of labour and between "blue and white collar" employees

Moving away from artisanal and craft production. No intelligence: Human power was substituted

Fig 1 The four industrial revolutions (based on Forschungsunion $(2012,13)$ and Hallward-Driemeier and Nayyar (2018, 41-44).

Masood, T. and Egger, J. (2019) 'Augmented reality in support of intelligent manufacturing - A systematic literature review', Computers \& 
Table 1 Review articles with the application and the focus of studies. The last column indicates which gap this paper tries to close compared to the other literature

\begin{tabular}{|c|c|c|c|c|c|}
\hline Authors & Year & Title & Application & Focus & Gap \\
\hline Dey et al. & 2018 & $\begin{array}{l}\text { A Systematic Review of } 10 \text { Years of } \\
\text { Augmented Reality Usability } \\
\text { Studies }\end{array}$ & $\begin{array}{l}\text { Collaboration, } \\
\text { Education, } \\
\text { Entertainment, } \\
\text { Industrial, Interaction, } \\
\text { Medical, Navigation, } \\
\text { Perception, Tourism }\end{array}$ & Technology usability & $\begin{array}{l}\text { - No current challenges highlighted } \\
\text { - Only } 30 \text { out of } 291 \text { reviewed papers have an industrial } \\
\text { context } \\
\text { - No in depth analysis of the current research of industrial } \\
\text { AR } \\
\text { - No studies after } 2014 \text { considered }\end{array}$ \\
\hline Fraga-Lamas et al. & 2018 & $\begin{array}{l}\text { A Review on Industrial Augmented } \\
\text { Reality Systems for the Industry } \\
4.0 \text { Shipyard }\end{array}$ & Shipbuilding & $\begin{array}{l}\text { Hard- and software } \\
\text { solutions, possible } \\
\text { architecture for AR in } \\
\text { shipbuilding }\end{array}$ & $\begin{array}{l}\text { - No systematic review } \\
\text { - Focus only on shipbuilding industry } \\
\text { - No in depth analysis of future research directions } \\
\text { - Review focuses on hard- and software solutions, not on } \\
\text { current research }\end{array}$ \\
\hline Palmarini et al. & 2018 & $\begin{array}{l}\text { A systematic review of augmented } \\
\text { reality applications in maintenance }\end{array}$ & Maintenance & $\begin{array}{l}\text { Current research status } \\
\text { and future research } \\
\text { directions }\end{array}$ & $\begin{array}{l}\text { - Only maintenance operations considered } \\
\text { - Does not consider broader context of current challenges or } \\
\text { future research directions (organisational or environmental) }\end{array}$ \\
\hline Nee et al. & 2013 & $\begin{array}{l}\text { Virtual and Augmented Reality } \\
\text { Applications in Manufacturing }\end{array}$ & Manufacturing & $\begin{array}{l}\text { System architecture, } \\
\text { technological challenges }\end{array}$ & $\begin{array}{l}\text { - No systematic review } \\
\text { - Does not consider broader context of current challenges or } \\
\text { future research directions (organisational or } \\
\text { environmental) }\end{array}$ \\
\hline Nee et al. & 2012 & $\begin{array}{l}\text { Augmented reality applications in } \\
\text { design and manufacturing }\end{array}$ & $\begin{array}{l}\text { Manufacturing and } \\
\text { Design }\end{array}$ & $\begin{array}{l}\text { Technology, industrial } \\
\text { applications, human } \\
\text { factors }\end{array}$ & $\begin{array}{l}\text { - No systematic review } \\
\text { - Does not consider broader context of current challenges s } \\
\text { or future research directions (organisational or } \\
\text { environmental) }\end{array}$ \\
\hline Carmigniani et al. & 2011 & $\begin{array}{l}\text { Augmented reality technologies, } \\
\text { systems and applications }\end{array}$ & $\begin{array}{l}\text { Advertising and } \\
\text { Marketing, } \\
\text { Entertainment, } \\
\text { Education, Medical, } \\
\quad \text { Navigation }\end{array}$ & $\begin{array}{l}\text { Focus on end-user } \\
\text { friendliness and end- } \\
\text { user applications }\end{array}$ & $\begin{array}{l}\text { - No systematic review } \\
\text { - Does not consider broader context of current challenges s } \\
\text { or future research directions (organisational or } \\
\text { environmental) } \\
\text { - No industrial applications reviewed }\end{array}$ \\
\hline
\end{tabular}

\section{Augmented Reality}

Contrary to common perception, AR has been around for the last five decades (Sutherland 1968). Recent leaps in miniaturisation and increased computing power made it possible to develop AR systems with capabilities relevant to consumers and industry. AR systems enable humans to access digital information through a layer of information positioned on top of the physical world (Kong et al. 2018). According to the widely used reality-virtuality (RV) continuum (Milgram et al. 1994), AR is positioned between the real environment and the virtual environment (see Fig 2).

The real environment and the virtual environment (also called virtual reality (VR)), are the two extreme points of the RV continuum. All the information is either real or virtual. Everything in between those extremes incorporates virtual and real elements and is called mixed reality (MR). MR incorporates $A R$, which augments the real world by adding virtual content. It also incorporates augmented virtuality (AV). AV augments the virtual world by adding real-world content. The differentiation between $A R$ and $A V$ is not distinct along the continuum. However, as long as the real content is dominant, it is AR. This contrasts the concept of $A V$ and VR, where a dominant proportion or all the information is presented virtually. Some researchers relate to AR only when the content is displayed in 3D (Azuma 1997). Within this document, the term $A R$ is used for $2 D$ and $3 D$ solutions.

The basic components of an AR system are the visualisation technology, a sensor system, a tracking system, a processing unit, and the user interface (Wang et al. 2016). The interaction between those components, their function, and the technologies used are shown in Fig 3.

\section{Visualisation technology}

This component visualises digital information within the context of the real environment. Four main visualisation technologies are available for AR systems, namely headmounted displays (HMDs), handheld devices (HHDs), static screens, and projectors (Milgram et al. 1994). The visualisation system can either be stationary or mobile.

\section{Sensor system}

The sensor system obtains information from the environment. For most of the AR system, the central input is one or several cameras. Stereo cameras provide depth perception. Other methods for obtaining depth information are ultrasonic, or infrared sensors (Wolfartsberger et al. 2017). When using mobile systems (HMDs or HHDs), different sensors, like gyroscopes or accelerometers are used to determine the position of the display (Fraga-Lamas et al. 2018).

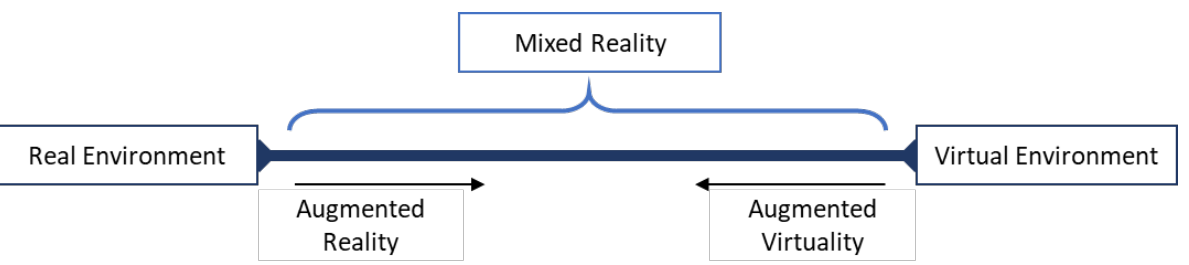

Fig 2 Reality-virtuality continuum (based on Milgram et al. 1994) 


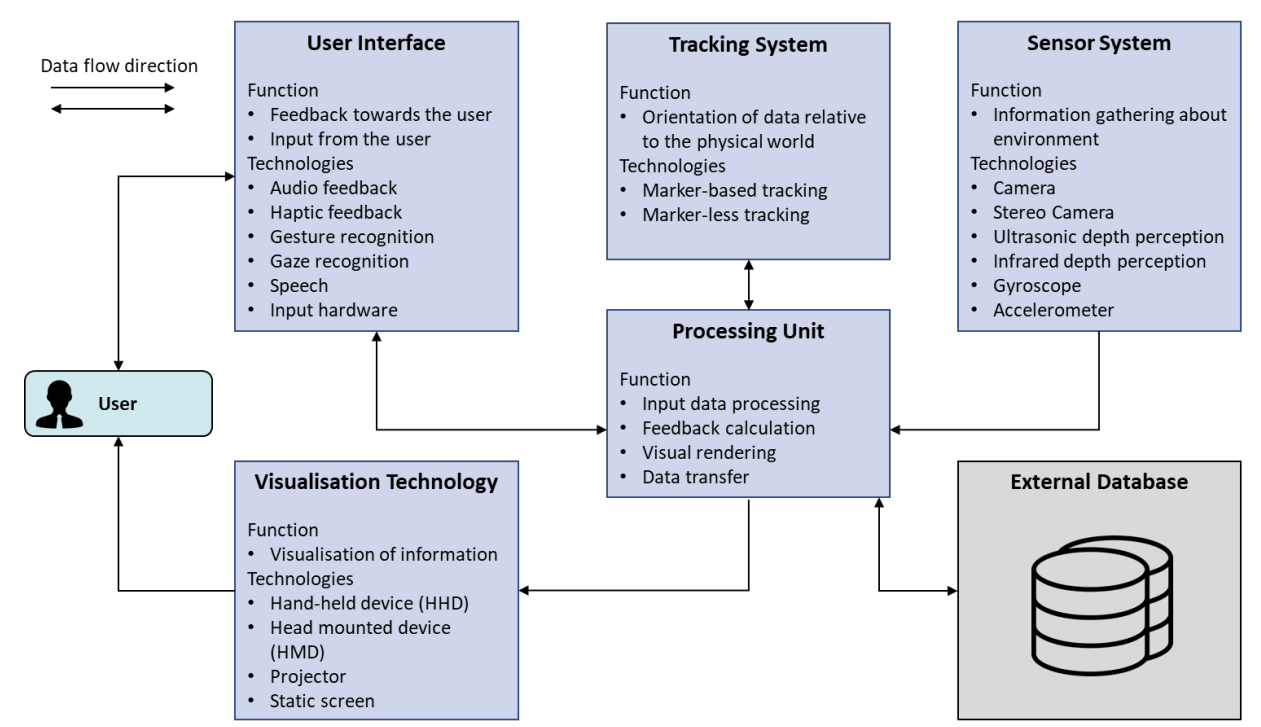

Fig 3 Components and their interaction of an AR system (based on Wang et al. 2016; Azuma 1997)

\section{Tracking system}

The AR tracking system enables digital objects to be placed accurately within the physical world. The most prominent AR technology is marker-based. Physical markers are attached to certain places. These AR markers are used to triangulate the correct position for a digital object. This technology is well understood and mature, but dirt, mechanical abrasion, or lightning conditions impede marker recognition. Natural marker or markerless systems require no additional physical objects attached to the real world to determine the position of virtual objects (Wang et al. 2018; Wu et al. 2016).

\section{User interface}

The AR user interface enables two-way communication from the system towards and from the user. Technologies, like force feedback (Majewski and Kacalak 2016), or acoustic cues (Zhou et al. 2007) are used. Prominent user input methods are gesture recognition (Wang et al. 2016), the direction of gaze (Park et al. 2008), speech recognition (Majewski and Kacalak 2016), or discrete hardware solutions. Discrete user input hardware can range from mouse and keyboard to handscanners (Murauer et al. 2018).

\section{Processing unit}

The processing unit is responsible for executing the software to run the AR system. In addition, it is the connection to other sources of data which can be obtained or provided in real-time.

\section{Methodology}

In this section, the methodology of the literature is described. A seven-step approach was used to extract the relevant information. This methodology was based on 'Producing a systematic review' (Denyer and Tranfield (2009) and on 'Systematic approaches to a successful literature review' (Booth et al. 2016). Fig 4 shows the steps and the outcome of each phase. 

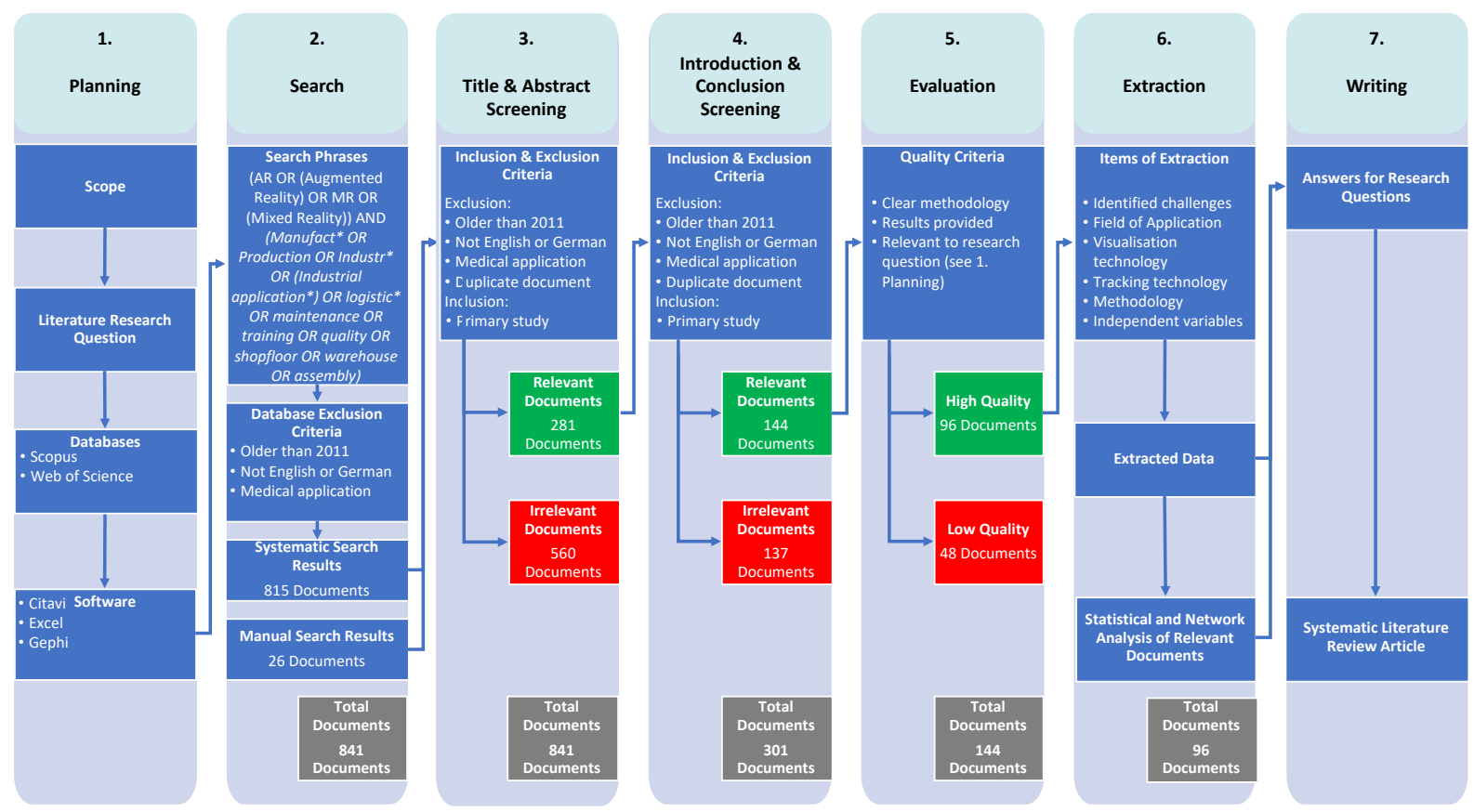

Fig 4 Research methodology for the literature review which consists of seven steps. Within each of these steps, the results of the process are displayed. The arrows indicate the process flow. The numbers indicate how many documents were retrieved, discarded

\section{Step 1: Planning}

The first step was to determine exactly which areas the research should cover, and which are excluded. This literature review was focussed on AR applications in manufacturing. Hence, the following research questions for the literature review were defined:

\section{Q1: What is the current status of manufacturing related AR research?}

The objective was to determine which AR systems were used, how they were tested and evaluated, what research focus areas within the different applications existed, and which authors and research clusters and institutions are involved in the research and connected with each other.

Q2: What are the current challenges that hinders the adoption of $A R$ in manufacturing?

The objective was to uncover the current issues within a broad context. Not only technological limitations were taken into account but also challenges arising from industrial implementations in an organisational and userfocused context, as this can give indications concerning the maturity of the technology.

Q3: What are future directions of manufacturing related $A R$ research?

Based on the reviewed documents and the results concerning Q1 and Q2, future research directions were identified and summarised. These research directions should give guidance for the next steps alleviating the limitations and challenges.
Then, the following databases were identified for search purposes:

- Scopus

- Web of Science

Those databases were chosen due to their broad coverage of journals. Citavi was used as a reference manager software. This program was selected due to its broad functionality, like auto-import, integrated pdfviewer, word citation add-in, or internal cross-referencing to link documents. Microsoft Excel was used as data extraction and evaluation tool.

\section{Step 2: Search}

To perform the systematic search, a set of search strings was defined to search the databases identified in step 1 . Through an assessment of previous literature reviews on AR (Nee and Ong 2013; Nee et al. 2012; Carmigniani et al. 2011), the areas of application and the search string were defined. The search string

\section{(AR OR (Augmented Reality) OR MR OR (Mixed Reality))}

\section{AND}

\section{(Manufact* OR Production OR Industr* OR (Industrial application*) OR logistic* OR maintenance OR training OR quality OR shopfloor OR warehouse OR assembly)}

incorporated different synonyms for the areas of application. In addition to 'Augmented reality', the key phrase 'Mixed reality' (MR) was also used. The reason is that not every author follows the same definition of $A R$ and MR. 
This step was also important for utilising the capabilities of the databases to limit the results to the relevant timeframe and the relevant area of interest. The exclusion criteria used within the database are:

- Not in English or German

As the authors of this literature review are fluent in both languages, this can be used to gain a broader view of the field. Due to the fact that AR is often used in the context of the German 'Industrie 4.0' initiative (Funk, Kosch and Kettner et al. 2016; Paelke and Röcker 2015; Paelke 2014; Kagermann et al. 2013), several research groups in Germany do research around industrial AR. Some of this research has been published in German.

- $\quad$ Older than 2011

The starting point of this literature review was the last literature review on AR in manufacturing published in 2012 (Nee et al. 2012). Due to the time discrepancy between conducting the research and publications, we deemed it necessary to also include studies from the year 2011 in this literature review. In addition, older studies become less relevant due to technological leaps forward.

- Not manufacturing or software engineering related

AR has a broad field of applications outside of the manufacturing industry; for example, marketing or medical applications. Those are outside of the scope of this literature review.

Table 2 shows the number of results from each database, which includes journal articles, review articles and conference papers. The search was conducted on $28^{\text {th }}$ of September 2018. In this step, neither the titles nor the abstracts of the papers retrieved were read. For both of the databases, the term augmented reality OR mixed reality was applied to the title, while the rest of the search phrase was applied to the title, abstract, and keywords.

Table 2 The table shows the number of results for each of the two databases searched with the search phrase

\begin{tabular}{clc}
\hline & & Number of Documents \\
\hline \multirow{2}{*}{ Scopus } & Papers found & 704 \\
& Irrelevant Papers & 468 \\
\hline \multirow{2}{*}{ WebOfScience } & Papers found & 111 \\
& Irrelevant Papers & 67 \\
\hline & Duplicates & 25 \\
\hline
\end{tabular}

As Greenhalgh and Peacock (2005) showed, it is not likely that all relevant documents are retrieved through a systematic database search. To counteract that issue, relevant literature found throughout the project through backward or forward citation screening was included as well. Table 2 shows the result of this process. Documents retrieved from the manual search entered the same process as the one from the systematic search continuing with step 3.

\section{Step 3: Title \& Abstract Screening}

The contents of the papers were assessed through screening of titles and abstracts. To do so, a catalogue of exclusion and inclusion criteria was developed by extending criteria of the database exclusion. The previously used criteria to restrict the database results were applied again, as the results showed that not all of the irrelevant papers were discarded by applying filters to the field of AR research.

Additional exclusion criteria:

- Duplicate document

Inclusion criteria:

- The primary study focused on manufacturingrelated AR applications

These criteria were drawn and adapted from a literature review (Palmarini et al. 2018) and literature giving guidance in that area (Buchanan and Bryman 2009; Saunders et al. 2009). Fig 4 shows the process of screening and evaluation and the number of papers not included due to the exclusion criteria in the respective step.

\section{Step 4: Introduction \& Conclusion Screening}

Utilising the same exclusion and inclusion criteria as in step 3, step 4 determined the relevance of a paper based on the introduction and the conclusion/discussion of the respective paper. Compared to step 3 , this step was a more in-depth selection of the documents. Otherwise, the process was the same. Fig 4 shows the process of screening and evaluation and the number of papers not included due to the exclusion criteria in the respective step. The result of the screening process was a list of 144 documents. These documents were imported into the reference manager Citavi. As the search was conducted within different databases, duplicates were removed in this step.

\section{Step 5: Evaluation}

At this stage, the articles were probed concerning their quality. Quality criteria were drawn and adapted from the same literature as for step 3 . Fig 4 shows the process of screening and evaluation and the number of papers not included due to the quality exclusion criteria in the respective step. Three quality criteria were used:

\section{Quality Criteria:}

- The methodology is clearly explained.

- Results are provided.

- The document is relevant to the research questions of the literature review.

The documents were assessed through a binary decision of compliance with the criteria. In the end, a decision was made if the paper will be looked into in detail within this literature review. However, it was not necessary to fulfil all of the criteria. For example, it was possible that a 
Table 3 The table shows a representative part of the data extraction document with the data points gathered for each of the documents entering step 6 . The original document includes several additional columns for the author to make remarks concerning the content of each paper.

\begin{tabular}{|c|c|c|c|c|c|c|c|}
\hline Authors & Year & Field & Technology & Aim & Methodology & Dependent Variables & Identified Issues \\
\hline Uva A.E. et al. & 2018 & Assembly & $\begin{array}{l}\text { Projection } \\
\text { Marker tracking }\end{array}$ & $\begin{array}{l}\text { Improve operator assembly performance } \\
\text { compared to paper based system }\end{array}$ & Lab experiment & $\begin{array}{l}\text { Time measurement } \\
\text { Error rate } \\
\text { User survey }\end{array}$ & $\begin{array}{c}\text { Distraction } \\
\text { Influence of experienced operators }\end{array}$ \\
\hline Doshi A. et al. & 2017 & Quality & Projection & Improve accuracy of manual spot welding & $\begin{array}{l}\text { Lab experiment } \\
\text { Field experiment }\end{array}$ & $\begin{array}{l}\text { Time measurement } \\
\text { weld location }\end{array}$ & Information display \\
\hline Stoltz M.-H. et al. & 2017 & Logistics & $\begin{array}{c}\text { HMD } \\
\text { Marker tracking }\end{array}$ & $\begin{array}{l}\text { Improve warehouse operations using the } \\
\text { example of sorting }\end{array}$ & $\begin{array}{c}\text { Field experiment } \\
\text { Lab experiment }\end{array}$ & $\begin{array}{l}\text { Time measurement } \\
\text { User survey }\end{array}$ & $\begin{array}{l}\text { Hardware selection } \\
\text { Information display } \\
\text { Cost } \\
\text { Social acceptance }\end{array}$ \\
\hline Wang $X$. et al. & 2016 & Assembly & $\begin{array}{c}\text { HMD } \\
\text { Static screen } \\
\text { Marker tracking }\end{array}$ & $\begin{array}{l}\text { Compare bare-hand gesture recognition AR } \\
\text { system to LCD based AR system and a paper } \\
\text { based system }\end{array}$ & Lab experiment & $\begin{array}{l}\text { Time measurement } \\
\text { Error rate } \\
\text { User attention }\end{array}$ & Feedback system towards user \\
\hline Hou L. et al. & 2015 & Assembly & $\begin{array}{c}\text { HMD } \\
\text { Marker tracking }\end{array}$ & $\begin{array}{l}\text { Test prototype AR system to show assembly } \\
\text { steps compared to paper based solutions } \\
\text { Define advantages in terms of task performance } \\
\text { and cognitive workload }\end{array}$ & Lab experiment & $\begin{array}{c}\text { User survey } \\
\text { Time measurement } \\
\text { Error rate }\end{array}$ & $\begin{array}{l}\text { Tracking } \\
\text { Portability } \\
\text { Cost } \\
\text { Social acceptance } \\
\text { Tracking technology }\end{array}$ \\
\hline Henderson S. and Feiner S. & 2011 & Maintenance & $\begin{array}{c}\text { HMD } \\
\text { Static screen } \\
\text { Marker tracking }\end{array}$ & Increase maintenance efficiency & Lab experiment & $\begin{array}{l}\text { Head movement } \\
\text { Time measurement } \\
\text { NASA-TLX }\end{array}$ & $\begin{array}{l}\text { Data display } \\
\text { User centred content } \\
\text { Multi-modal information } \\
\text { Multi-modal communication }\end{array}$ \\
\hline
\end{tabular}

document was included despite lacking methodology due to an interesting concept.

\section{Step 6: Extraction}

The first part of this section explains the methodology of the network analysis, then the extracted items are explained in detail.

From the extracted papers, a citation network analysis was conducted to determine research hubs and the interconnection between the papers selected. The method was based on similar analyses conducted (Wilding et al. 2012; Kajikawa et al. 2007), however, the goal was to classify research hubs around the world, and not the development over time. To do so, the relevant papers were imported into the network analysis tool 'Gephi' (Version 0.9.2) as nodes. Afterwards, all backwards citations of the papers were imported as nodes as well and linked to the main document. This step created the edges between the nodes. Then, the digital object identifier (DOI) was used to merge all duplicates within the backward citations. As the edges were maintained when merging nodes, the network was created at this step. To manage the large network, nodes were filtered based on the following criteria:

\section{- 'Giant Component'}

All nodes not connected to the main network were filtered.

\section{- 'Degree range'}

In this setting, all nodes with less than two edges (less than $2 x$ cited) were filtered from the citation network analysis, but not from the review.

Afterwards, an in-built modularity algorithm (Lambiotte et al. 2014) was used to determine communities within the network. In the end, the Yifan Hu algorithm (Hu 2006) was used to obtain the layout. This force-based algorithm was used to draw graphs and is an inbuilt function of gephi. Those communities are analysed qualitatively to determine tendencies of certain authors and research institutions contained within a community.

In order to systematically extract information from the relevant documents, a table was generated. Within this table, the articles were inserted in the first column as rows and different characteristics of the AR system and the study as columns. Table 3 shows a representative extract of this document. The selection of the characteristics is based on other successful literature reviews and on the aim of this literature review. The different data extraction points will be discussed in the following section.

\section{Field of application}

Here, it is defined for which application an AR system has been developed or tested. Depending on the category, different requirements need to be met by the AR system.

Initially, the following categories were defined within step 2 of the review:

- Maintenance
- Assembly
- Quality
- Logistics
Others

Step 4 and 5 showed, that a low number of papers focused on the areas outside of the maintenance, assembly, quality, and logistics. Those papers were summarised in the category 'Others'. These include AR for Supervisory Control and Data Acquisition (SCADA) or machining/machine set-up applications.

\section{Technology}

There are different ways to visualise the AR content for the user. Those were classified in four different categories:

- $\quad H M D$

- $\mathrm{HHD}$

- Static Screen

- Projector 
In order to superimpose digital content at the right place in and dynamic system where the visualisation device and/or the parts of the environment are physically moving, tracking is essential. The different approaches to do so are classified as follows:

- $\quad$ Marker tracking

- Marker-less tracking

- Natural marker tracking

\section{Methodology}

From the results (see Table 2) different methods to test AR applications were defined. They have been divided into the following categories:

- Laboratory experiment

- Field experiment

- Simulation

- Pilot project

Some papers presented work on prototypes at early stages without results of their performance (Jayaweera et al. 2017; Kocisko et al. 2017; Schlagowski et al. 2017; Wolfartsberger et al. 2017; Flatt et al. 2015; Rodriguez et al. 2015). As the developed prototypes had interesting features, those papers were added to the literature review despite them being not tested rigorously. They are classified under 'Pilot project'.

The classification between laboratory and field experiment was not clear in every case. For this literature review, studies that were conducted in a factory environment are classified as field experiments. In addition, studies that recruited technicians, workers, etc. as participants for simulations of shop-floor tasks in a laboratory were classified as field experiments. The reason for this classification was that these studies give insights into the real-life applications and problems when deploying $A R$ in industrial environments. The study participants would be the users of the technology within an industrial setting and appreciate the challenges posed by such an environment compared to e.g. students who participate. Additionally, the real-life inspired tasks within the study needed to be taken from real-life manufacturing applications. Despite the fact that those experiments were conducted not in the field, the authors of this literature review saw the value of those experiments modelled close to real-life applications despite not being conducted within a factory. Thus, they were regarded closer to field experiments than laboratory experiments with students as participants and/or tasks not directly related to manufacturing applications.

\section{Metrics}

Different studies use different metrics to determine the capability of the prototype. The following metrics were used:

- $\quad$ Time (for example (Uva et al. 2018))

- $\quad$ Error rate (for example (Uva et al. 2018))

- NASA Task Load Index (TLX) (for example (Murauer et al. 2018))
- User surveys (for example (Uva et al. 2018))

- Marker decoding distance (for example (Koch et al. 2014))

- Marker decoding time (for example (Koch et al. 2014))

- Head movement (for example (Renner and Pfeiffer 2017))

- Weld location (for example (Doshi et al. 2017))

\section{Challenges}

In order to answer the second research question (Q2: What are the current challenges that hinders the adoption of $A R$ in manufacturing?) posed, it was necessary to determine the current limitations and challenges when utilising AR technologies. To do so, a hierarchical structure is used to classify the challenges extracted from the documents in the review. The threetiered structure classifies issues into a 'technology', an 'organisation', and an 'environment' part. Within those classifications, the issues are labelled.

\section{Current Status}

To answer the first research question posed (Q1: What is the current status of manufacturing related $A R$ research?), this section first looks into the findings of the network analysis. Then, the overall status of the research concerning AR in manufacturing applications is described. To conclude this section, each of the fields is analysed in more detail to draw the recent history and developments within the last seven years.

\section{Network Analysis}

In this section, the network analysis conducted is discussed. The goal was to determine where the manufacturing related $A R$ research hotspots are, if and how they are interconnected, and if different areas focus on different aspects of AR research. This can lead to a better understanding of the research landscape and, thus, a better understanding of the current research status.

Fig 5 shows the network generated. The size of a node indicates the number of citations. Every edge represents a backward citation. There is no weight of some sort applied to the edges. The node colours indicate the different clusters identified.

The modularity algorithm used in gephi (Lambiotte et al. 2014) uncovers communities, called classes, within networks based on the structural and statistical properties of the network. The colour coding in Fig 5 shows the three classes uncovered by the modularity algorithm. It was overserved that class 1 (red) is not as tightly packed by the modularity algorithm used compared to class 2 (blue). This means, that the documents in class 1 tend to have a lower number of citations within that network (backwards and forward). This can be explained by the fact that the density of authors with a high output and, thus, the number of citations within that network, was higher in class 2 . In addition, no differentiation between articles and 
conference articles was made in this literature review, which possibly could explain the difference to some extent.

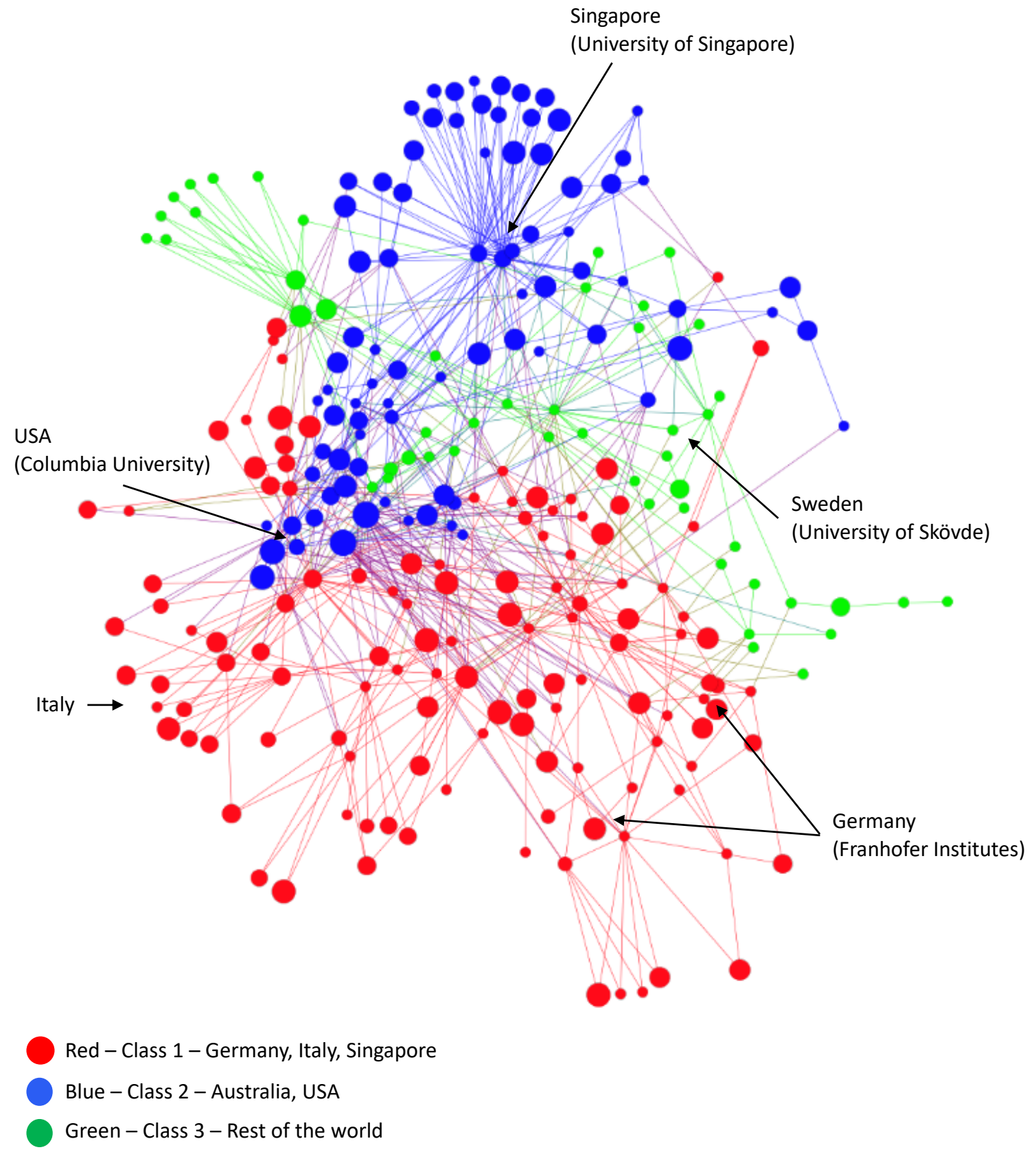

Fig 5 Citation network with colour coded classes and indication of research clusters within the classes. The size of the nodes indicates the number of citations.

Table 4 defines the geographical region, the most important research institutions, and influential authors within each class. Even within the classes, certain research institutes and/or countries have their distinct locations. The arrows and the description in Fig 6 indicate those areas. Germany was the country with the single most publications according to the initial search string (at step 2 of the methodology). When adding the documents of the Fraunhofer Institutes up, they did the most research in that area (at step 2 of the methodology). When looking at individual authors, Nee and Ong were the two authors with the most publications (at step 2 of the methodology). 
Table 4 Geographical region, important research institutions, and relevant authors for each of the classes identified.

\begin{tabular}{ccccl}
\hline Colour & Region & \multicolumn{1}{c}{ Institutions } & \multicolumn{1}{c}{ Relevant Authors } \\
\hline \multirow{2}{*}{ Class 1 } & red & Germany & Fraunhofer Institutes & Funk, M. \\
& & IU Munich & Reif, R. \\
& & Italy & Politecnico di Bari & Uva, A.E.; Fiorentino, M. \\
& & Singapore & University of Singapore & Ong, S.K.; Nee, A.Y.C. \\
Class 2 & blue & Australia & University of South Australia & Lee, G.A. \\
& & US & Curtin University & Wang, X. \\
& & & Columbia University & Henderson, S. J.; Feiner, S. K. \\
Class 3 green & Rest of the World University of Skövde (Sweden) & Syberfeldt, A.; Holm, M. \\
\hline
\end{tabular}

The three classes identified were mainly differentiated by geographical region. There are some exceptions to this. A paper from researchers at the TU Chemnitz (Germany) (Kollatsch et al. 2014) was part of class 2 and a paper from researches based at the University of New South Wales (Australia) and Curtin University (Australia) (Hou et al. 2013) was classified in class 3 . However, the general trend was clear. The research groups in certain geographical areas cite mainly research from that geographical region.
Yet, the different identified classes were far from being isolated. Fig 6 shows only the edges, thus the citations. The colour of an edge corresponds to the nodes it is connected with. If an edge is connected with two nodes from the same class, it has the colour of that class. If an edge is connected with two nodes from different classes, the colour is a mixture of the colours of each class. Especially the US researchers in class 2 had tight connections with the studies from Germany and Italy.

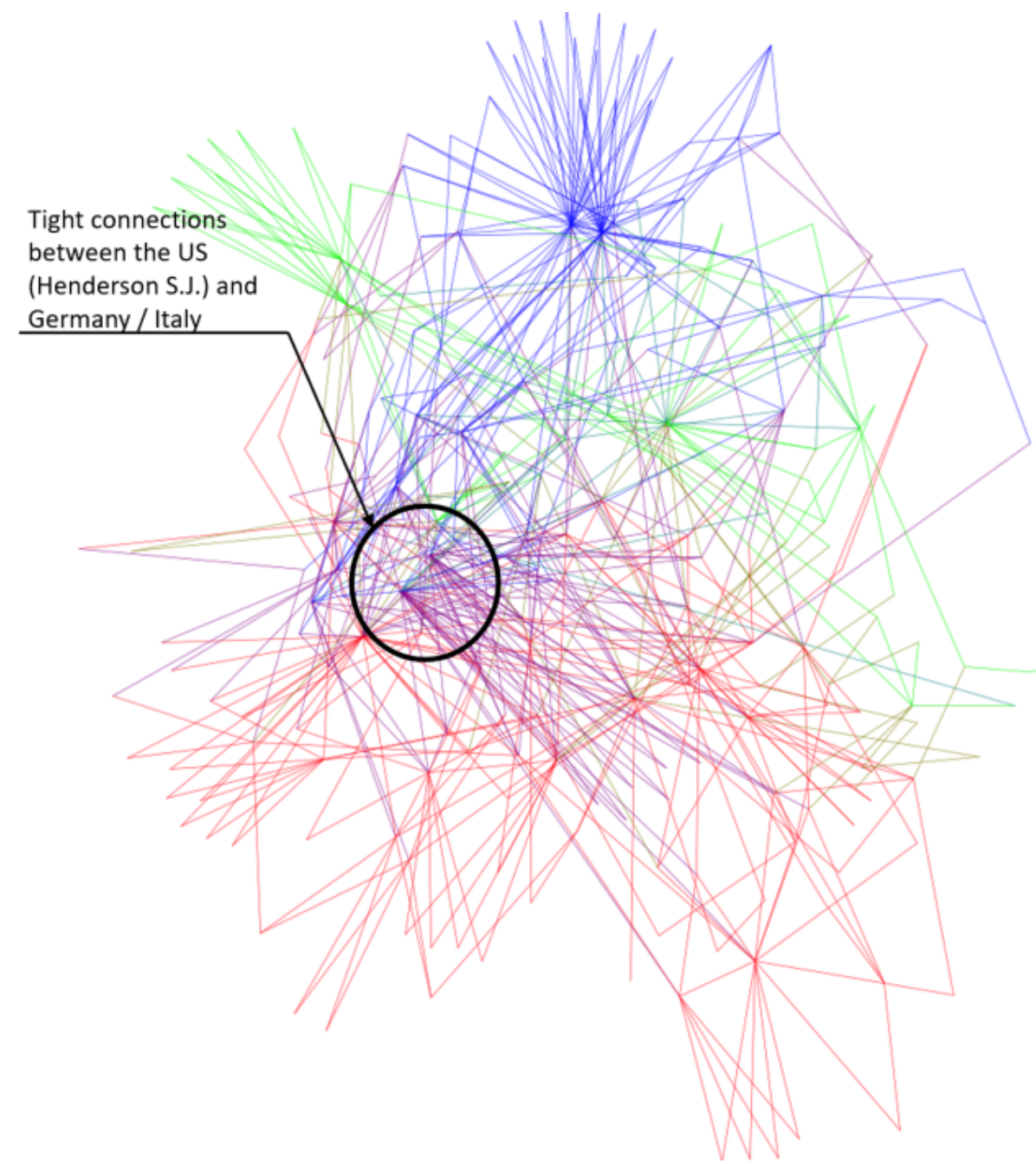

Fig 6 Colour coded edges of the citation network. The circle indicates a close connection of class 1 and class 2; mainly through US authors

Masood, T. and Egger, J. (2019) 'Augmented reality in support of intelligent manufacturing - A systematic literature review', Computers \& 


\section{Results of Data Extraction}

In this section, the findings of the extracted data are analysed for all papers extracted.

\section{Field of application}

Compared to VR, AR can be used in environments, where the real world is relevant as well and additional information can benefit operators. AR can be used for assembly operations in intelligent manufacturing, either in training (Werrlich et al. 2017; Hahn et al. 2015) or as a live guidance system for operators (Blattgerste et al. 2017; Funk et al. 2017). In logistic, 'pick-by-vision' is a prominent concept utilising industrial $A R$ to indicate picking locations and quantities (Hanson et al. 2017; Renner and Pfeiffer 2017; Guo et al. 2014; Reif et al. 2009). Another area of logistics where AR can be used are general warehouse operations (Stoltz et al. 2017). Additional prominent fields of applications include quality assurance (Antonelli and Astanin 2015; Segovia et al. 2015) and maintenance (Martinetti et al. 2017; Masoni et al. 2017; Mourtzis and Zogopoulos et al. 2017; Palmarini et al. 2017; Zhu et al. 2012). As soon as operators depend on or can profit from (real-time) information, AR can be used to intuitively display this information on site.

By providing flexible real-time information and the possibility of obtaining information hands-free AR can offer a substantial efficiency benefit (Guo et al. 2014; Hou and Wang 2013) by decreasing the error rate (Wang et al. 2016), like picking or assembly errors and it provides easy ways to communicate with experts in maintenance tasks (Mourtzis and Vlachou et al. 2017).

Fig 7 shows the percentage of the included documents focused on a certain field of application. Assembly and maintenance together account for nearly $75 \%$ of the relevant documents. 43 documents were classified in the 'assembly' field of application.

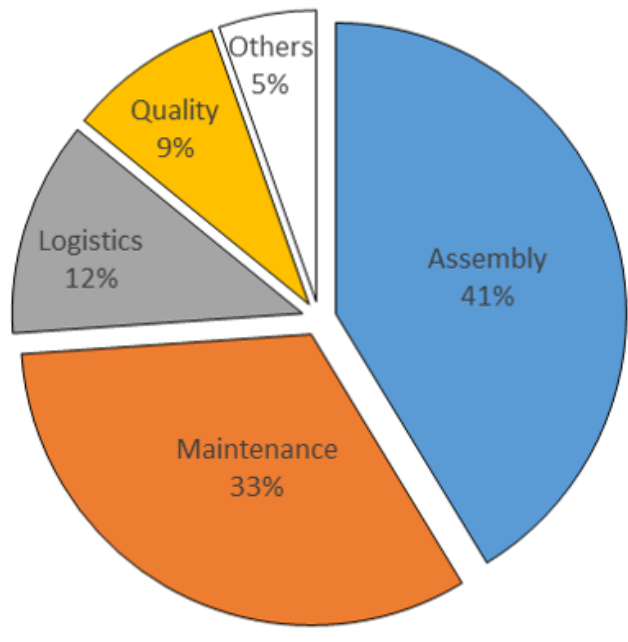

Fig 7 Distribution of the different fields of application for each of the documents reviewed
$35 \%$ of the documents focused on maintenance, as the second part of the pie-chart shows (see Fig 7). One of the documents stated that the developed system is viable for both, assembly and maintenance. However, due to the focus of the paper on assembly, it was classified accordingly (Sanna et al. 2015).

The next slice (see Fig 7) focuses on logistics. While picking supported by AR (also called 'pick-by-vision') has already 'come of age' (Reif et al. 2009), the research now on tends to focus other applications within logistics, for example peripheral equipment (Murauer et al. 2018) and safety-related aspects (Sarupuri et al. 2016), or on very specific problems within picking, like peripheral equipment (Murauer et al. 2018).

\section{Technology}

A crucial part of an AR system is the visualisation technology used to display the digital content to augment the environment. Fig 8 shows the number of studies utilising a certain visualisation technology. The most dominant devices used were HMDs followed by HHDs. It should be noted that some studies used more than one visualisation technology. Their usual aim was to compare the performance of those technologies. Especially the price and the availability of HHDs make them attractive for use. Static screens are often used as the first proof of concept before further developing the system. The learnings of a first test-run were then used when porting the application onto HHDs or HMDs.

Another essential component is the tracking technology used to place the digital content correctly. The vast majority used marker tracking systems. Three studies developed (Wang et al. 2018; Crescenzio et al. 2011) or used marker-less tracking systems (Flatt et al. 2015). Here, the environment itself is used to anchor the digital content. Another approach is to use natural markers. Here, dominant physical pictograms or objects are used instead of dedicated markers (Koch et al. 2014). This system, however, does not seem to be promising, as to more recent research focuses on entirely marker-less systems. 


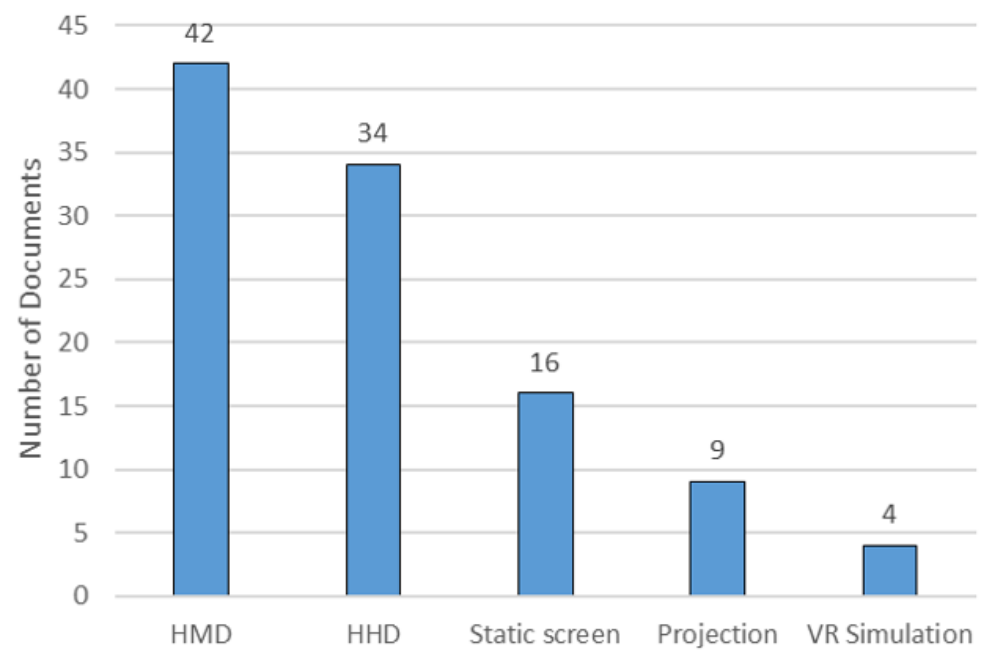

Fig 8 Number of documents that used a certain visualisation technology. It has to be noted that several studies utilise more than one technology

\section{Methodology}

Fig 9 shows the number of papers reviewed utilising a certain methodology throughout the years 2011 to 2018.
The height of the bar and the number above each bar shows the total number of papers reviewed from that year. The stacked bars indicate the number of papers utilising a certain methodology.

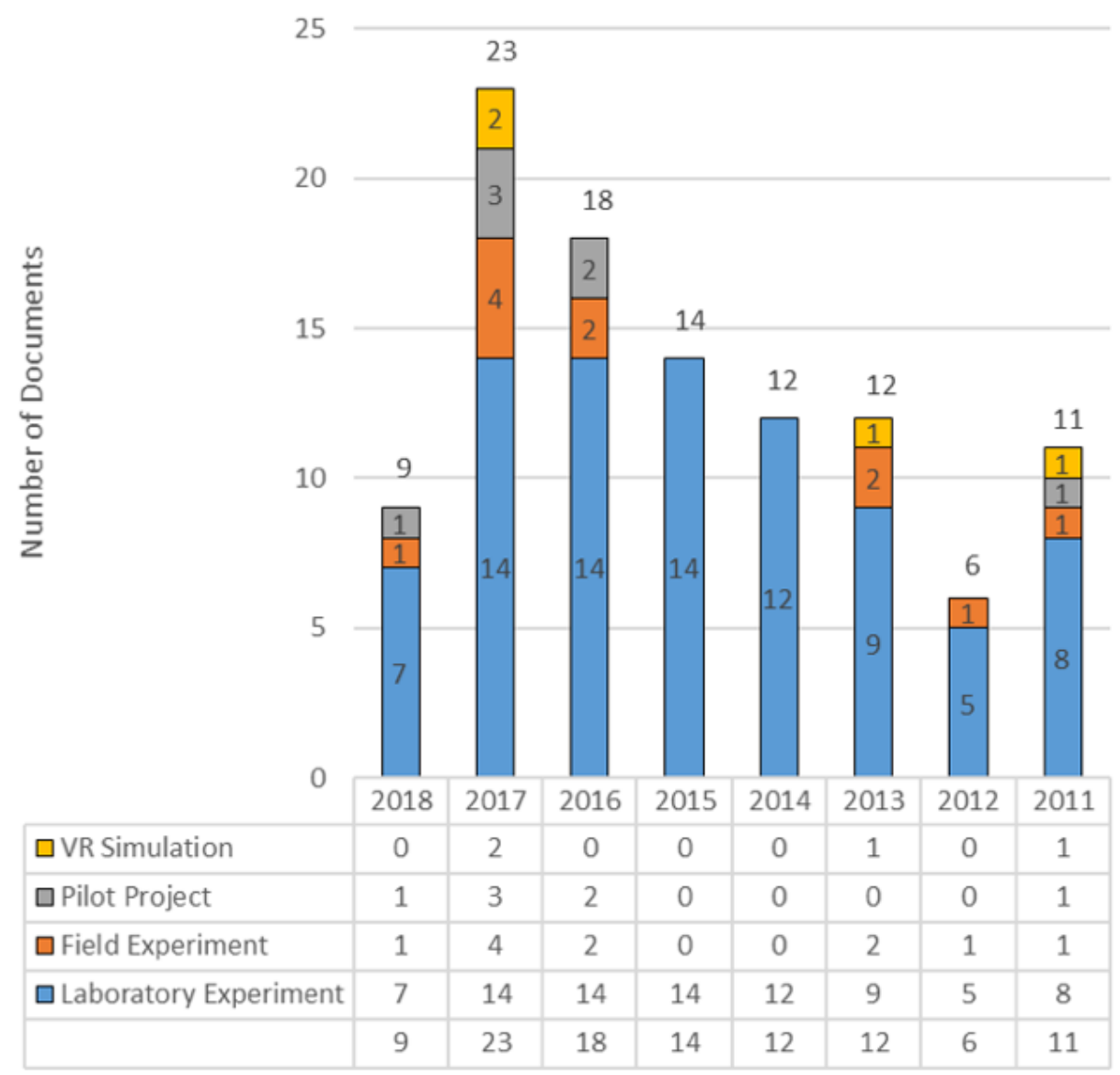

Fig 9 Number of studies that utilised a certain method to assess an AR system. It should be noted that some studies utilise more than one method. 
The vast majority of experiments were conducted within a laboratory setting (see Fig 9). Some utilised laboratory and field experiments within one study. Interestingly seven out of the 11 field experiments were conducted within the 2015-2018 period, showing an immense interest from the AR research community. Only four of the documents retrieved that were published prior to 2015, a field study was reported. Another approach used to compare different methods of $A R$ support and conventional methods is VR simulation. A task was modelled completely digitally using different methods of augmentation and even conventional paper-based information visualisation are simulated (Renner and Pfeiffer 2017; Renner and Pfeiffer 2017; Lee and Akin 2011).

\section{Measures}

Fig 10 shows the percentage of papers utilising a certain dependent variable. The most prominent measures to characterise the AR system were the time to task completion, the error rate, and the NASA TLX. Especially those three measures were often used within the same study.

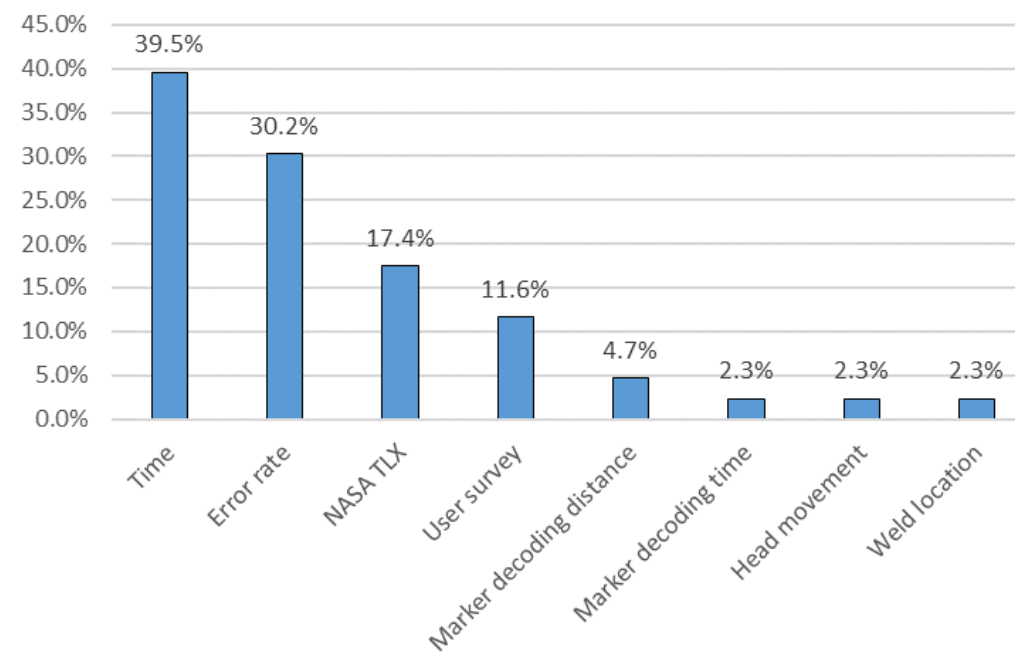

Fig 10 Percentage of studies that utilised a certain measure to assess an AR system. It should be noted that most of the studies utilise more than one measures

The different studies had different goals. Most of them focused on the possible improvements of a certain task through the AR system. Thus, the time to complete a task and the error rate were the most prominent measures used. Another focus was the usability of the system. For that reason, the NASA TLX (Hart and Staveland 1988), other user surveys, or the head movements were utilised as measures. However, some studies included in this literature review focused on the tracking technology itself (see Fig 10). It should be noted that most of the studies use more than one of those measures.

\section{Assembly}

Since the early beginnings of AR, it has been envisioned as a tool to support assembly workers (Azuma 1997) in intelligent manufacturing systems. Increasing product complexity and growing numbers of product variants have an impact on the assembly difficulty. Several authors state that AR can be used to counteract those difficulties (Funk et al. 2017; Holm et al. 2017; Wójcicki 2014). In addition, AR can decrease the learning curve (Hou et al. 2013) and supervise assembly steps by suggesting corrective measures once a mistake is detected (Mura et al. 2016).

\section{Performance of AR in Assembly}

The main focus of current research is determining the performance increase induced by AR guidance in different assembly scenarios. The most common measures used to quantify that efficiency increase are time and an error rate analysis. In addition, user surveys and surveys based on the NASA-TLX are commonly used to determine if the psychophysiological impact of the technology. Fig 10 shows what percentage of studies used those measurements.

A research at Curtin University in Australia focussed on the learning curve effects (Hou et al. 2013). In Hou et al. (2013), an AR static screen solution and paper-based instructions are compared for assembling a Lego model. They find that the error rate and the time necessary to complete the model is lower when using AR for assembly guidance. In addition, the cognitive workload of using AR in the static screen setup is lower. Another significant finding is the steeper learning curve when using AR as a training system for assembly novices. Hořejší (2015) confirmed a steeper learning in a rudimentary study of piping assembly training. In a follow-up study by Hou and Wang (2013), a difference of the learning effects between gender was analysed. They found that there is no significant difference when utilising AR as guidance. 
A more complex assembly task was studied by Hou et al. (2015) as well. Again, an AR static screen solution and paper-based instructions were compared. In this instance, the task was to assemble a complex 3D piping system. Again, the AR solution proved to be superior in all categories of measurement. However, it has to be noted that the paper-based instructions were 2D isometric technical drawings. None of the test subjects had previous experience with such drawings but only received a brief introduction on how to read such isometric drawings prior to the assembly tasks.

Several other studies also confirm the superiority of AR guidance for assembly in laboratory experiments (Bosch et al. 2017; Chang and Jau 2016; Hahn et al. 2015; Sanna et al. 2015). Henderson and Feiner (2011) showed that AR is superior in completion time, but that the degree of performance increase depends on the nature of the physical manipulation itself. Especially complex assembly steps profit from AR in this study.

Most of the studies above utilised different assembly scenarios to determine the performance of AR systems. However, it is hard to compare those studies, as the task complexity, the setup, and the measurements differ. Funk et al. (2015) proposed a standardised experimental setup to evaluate AR solutions. This system is based on a Lego assembly task. Thus, it is easy and cheap to replicate. They utilise the set-up to compare HMDs, HHDs, projection, and paper-based instructions (Funk, Kosch and Schmidt 2016). In contrast to previous studies, only the projection solution was slightly superior to the paper-based guidance in every regard (time, error rate, subjective task load). A solution utilising an HMD was inferior to the paper-based solution in every regard.

Blattgerste et al. (2017) used by Funk et al. (2015) developed an experimental setup to replicate the study. They critiqued how the HMD was used in the previous study and showed that another approach using a Microsoft HoloLens HMD leads to performance improvement as compared to paper-based instructions. The main difficulty in this experiment is to find the correct colour of the Lego blocks. This is not representative of complex 3D assembly operations. However, this controversy confirms that there is no 'one fits all' solution for AR supported assembly. The selection of the hardware and the implementation from a software side needs to be tailored to the specific task.

Another issue with the aforementioned studies in this section are the users. All authors recruited test subjects for lab experiments from a university background. This can influence the findings, as indicated by Sanna et al. (2015). Another study of the research group at the Human-Computer-Interaction laboratory at the University of Stuttgart looked into that issue (Funk et al. 2017). In their long-term field experiment at a car manufacturer, they compared the performance of expert and untrained workers when using an AR projection system. The expert workers were already accustomed to the assembly task, as this part has been produced for years. The effects of in-situ projection AR for the manual assembly of engine starters for a total of eleven days at an automotive assembly plant was studied. Each participant assembled for three days using the projectionbased AR system, which provided context-aware instructions. For both groups, the time to complete the task was surprisingly higher when using the AR projection system. In general, projection-based solutions are mainly used for assembly tasks, as they are stationary (Sand et al. 2016). Uva et al. (2018) used a similar setup but in a laboratory experiment, where all participants were students but no professional workers. The results showed AR superiority concerning completion time and error rate over a paper-based solution. The limitation of worker experience, however, is acknowledged.

The long-term results of the field study done by Funk et al. (2017) indicate that the expert workers get distracted by the system, but the difference between using the system and not using the system diminished over time. For novice workers, the benefit of the AR system was visible during the learning phase at the beginning of the experiment. After that, the AR system slowed them down. Holm et al. (2017) tried to tackle that problem of inflexible guidance by providing adaptive instruction through AR. Depending on the stored competence level of the user and the real-time completion time of a task, the visual guidance is adapted from basic text instructions to $3 \mathrm{D}$ animations. Another approach to show dynamic content based on the actions of the assembly worker is to detect assembly errors and show corrective measures (Mura et al. 2016).

\section{Human-robot collaborative assembly}

Another active research field of AR supporting assembly operations is improving the human-robot collaboration. In general, collaborative robots are designed to prevent health and safety issues for humans. Their maximum load and speed are limited. In addition, the physical design prevents any injuries from clamping or collisions. Two prominent examples are the $A B B$ YUMi (ABB AG 2018) and the KUKA LBR iiwa (KUKA AG 2018). Those limitations prohibit using these robots in collaborative assembly tasks where heavy loads need to be manipulated. Usually, industrial robots need to be within physical or virtual safety areas preventing anyone from entering proximity while the robot is moving. Pai et al. (2014) developed an AR system allowing for safer online programming of industrial robots.

The results published by Michalos et al. (2016) and Makris et al. (2016) stem from the Laboratory for Manufacturing Systems and Automation at the University of Patras developing an AR system for human-robot collaboration. One of their main goals is to enhance safety when working with robots originally not designed for collaborative tasks. Their solutions consist of visualising safe working areas (volumes), using audio-visual cues to indicate danger, and a visual representation anticipating the movement of the robot. 


\section{Gesture Recognition}

User interaction is a critical part of AR systems. Their usability has a profound impact on the performance of the system (Murauer et al. 2018). Saxen et al. (2017) state that user-friendliness is an important factor for the user acceptance. A focus of research concerning user interaction is hand gesture recognition. While this is applicable to all fields of applications, the relevant papers in this literature review address the issue of gesture recognition within the context of assembly tasks. Hence, it is covered in this section.

Earlier attempts to develop such a system by $\mathrm{Wu}$ and Wang (2011) and Radkowski and Stritzke (2012) focused on a digital task without guiding a physical assembly. Wang et al. (2016) developed a solution to navigate through digital AR manuals for assembly tasks. In addition, it can be used to manipulate digital objects. The comparison of an interactive system, an AR system navigated by mouse and keyboard, and a standard assembly manual displayed on a screen showed the advantages of the interactive AR system. The average completion time for a certain task dropped from approximately 32 seconds with the conventional manual to nearly 12 seconds while also decreasing the error rate. Additionally, the usability was superior. Despite not showing results for user performance, Saxen et al. (2017) demonstrated the reliability of such a system, classifying more than $99 \%$ of gesture correctly.

\section{Maintenance}

With the increasing complexity of machinery and industrial facilities, having information readily available can improve the economics of assets (Masood et al. 2018). Over the lifetime of machinery, the maintenance processes can account for a substantial part of the total cost of ownership. Lamberti et al. (2014) estimated a maintenance cost decrease of up to $30 \%$ for industrial machinery when utilising AR. Especially topics like improving the communication between an off-site expert and an on-site technician through augmented reality, conducting the maintenance operation itself, and the authoring of content are prominent in the current research.

AR-enabled maintenance can also harness the benefits of predictive maintenance. The move from a fixed maintenance schedule to an adaptive one based on realtime data can be supported by AR. The flexibility of maintenance workers can be increased by showing the right data at the right time for a certain maintenance task (Schlagowski et al. 2017; Flatt et al. 2015).

\section{Tele-maintenance}

The idea of improving maintenance operations through AR has been around for more than two decades (Azuma 1997). The main idea is to utilise off-site experts to improve maintenance operations. Usually, the communication is based on phone calls and electronic data exchange of pictures and descriptions. In order to improve the communication between the off-site expert and the on-site worker, AR can be used within the data exchange system (Leutert and Schilling 2015).

Masoni et al. (2017) describe such a system, where offsite experts utilise annotations, arrows, and other visual symbols which are then directly displayed by an AR application on the client side. The system uses natural markers; hence no artificial markers are necessary to determine the position of the visual clues. A similar system developed by Wang et al. (2014) is marker-based. According to Porcelli et al. (2013), using such AR telepresence systems can alter the whole service delivery system. The findings are based on a field experiment with several field operators using AR telepresence systems. The utilisation of highly skilled central operators can improve while optimising the education and the skill set of field workers. However, it is stated that this would call for significant organisational changes. Hence, the mindset within the organisation and the organisational structure itself can impede implementation of such a technology.

Lamberti and Pescador (2018) uses a prototype AR system for electronics maintenance, despite mentioning the airline industry as one of the industries with the highest percentage of maintenance of the total cost of ownership. However, future applications will be focused on industrial machine tools. A system is used that allows an operator providing assistance for technicians on site, but also allows the operator to author and alter content for maintenance operations.

Aschenbrenner et al. (2016) focus on the off-site expert side of telemaintenance and how to improve their situational awareness of the whole production process and peripheral machinery etc. Their 'ARTab' concept uses $A R$ on the other side of the telemaintenance collaboration than the studies above. While their system seems to improve situational awareness compared to VR or video solutions, it is not completely clear how the interaction between operator and field technician can be integrated into the system.

\section{Maintenance Operation}

A central part of AR in maintenance is the visualisation of maintenance procedures that are usually paper-based. Similar to displaying assembly steps, different maintenance tasks can be visualised step by step. Like other applications, using AR in laboratory experiments for maintenance tasks increases efficiency (Jayaweera et al. 2017; Mourtzis and Vlachou et al. 2017; Mourtzis and Zogopoulos et al. 2017; Fiorentino et al. 2014; Lamberti et al. 2014; Lee and Akin 2011). They provide evidence of AR superiority compared to paper-based maintenance instructions with regards to time to completion, error rate, and usability.

Two studies reporting on field experiments connected to maintenance were retrieved. A field experiment at a white goods manufacturer was conducted (Mourtzis and Vlachou et al. (2017). In this study, authors confirmed experimental results leading to a decrease in maintenance time of more than $50 \%$. However, it has to 
be pointed out that the study not only focussed on the use of augmented reality but also looked into workflow improvement through software integration. Another exception is the study by Porcelli et al. (2013) as discussed above. However, no quantitative results have been used to validate the improvement due to AR.

At the Fraunhofer Institute for Casting, Composite and Processing Technology in Augsburg, Germany, a Microsoft HoloLense based system is used to develop a human-centred assistance system for maintenance tasks of a CNC lathe (Schlagowski et al. 2017). The currently published status of their research is a prototype test focusing on the assistant functions. However, one of their general research goals is to incorporate big data concepts into the architecture to advance the prediction of maintenance work. Mourtzis and Zogopoulos et al. (2017) also focussed on data integration and connecting different stakeholders. They utilised AR within the Product-Service System (PSS) between a machine tool manufacturer and the company operating the machine tool. The core of their proposed solution is a cloud-based platform automating the communication and integrating the data capturing within one system. Preliminary field experiments showed promising results.

The CARMMI (Portuguese acronym for 'CAx models integrated to Mixed Reality and Intelligent Maintenance') ties together data from different sources (Espíndola and Fumagalli et al. 2013; Espíndola and Pereira et al. 2013). While the data extraction and visualisation include different sources of data, it is acknowledged that there are still data sources to consider, like product lifecycle management databases. Another issue anticipated in this study was the difficulty in technology adoption on the shop-floor level. Even though without having evidence on that topic, Espíndola and Fumagalli et al. (2013) argue that organisational processes need to be in place to fully utilise the new tool.

\section{Authoring}

Another active research area in AR maintenance applications is authoring for intelligent manufacturing systems. Creating content for AR maintenance systems can be challenging due to the complexity of the system and the tasks itself. In order to improve the efficiency of the authoring process and to give workers with no prior experience in computer science the ability to do so, easy authoring concepts are necessary. Havard et al. (2015) introduced a framework to create such content without programming skills. In addition, those systems should be context-aware.

In several papers included in this literature review, the content is created offline by developers. It can be beneficial to enable on-site technicians to adapt information within the system (Erkoyuncu et al. 2017). Then, it is possible to utilise their knowledge and their field experience. Zhu et al. (2012) proposed a bidirectional authoring tool where technicians are able to alter the maintenance contents on-site. Not only altering the content on-site but also creating the content in the first place is important (Espíndola and Fumagalli et al. 2013). Complex conventional manuals need to be translated into AR suitable content, which can be a timeconsuming task. Engelke et al. (2015) developed a system by which technically skilled people are able to easily transform traditional content into AR content. In order to enable dynamic on-site information creation, Flatt et al. (2015) introduced a system where digital 'sticky notes' can be placed on machinery. They can contain dynamic information, like process parameters, or static information, like reminder messages.

\section{Quality}

The visualisation of quality data on site through AR can improve the reaction speed and failure investigation. Segovia et al. (2015) use a system to visualise quality data on each workstation through an HHD. However, the solution only shows rudimentary functionality and does not integrate quality data management systems.

Sampling is a crucial part of quality control. A subset of finished products is inspected. The product selection from a pallet or a batch is often determined by a (statistical or probabilistic) logic within an MRP system. In order to decrease human errors, Franceschini et al. (2016) developed a prototype to identify the products for inspection within a pallet. The focus of this study is the technical realisation of such a marker-based system. No trials have been conducted yet if such a system would decrease the error rate or increase efficiency in that task.

Despite automated robotic based spot welding being the state of the art for body-in-white car manufacturing, the inspection of these welding spots is still done manually to some extent. Zhou et al. (2011) tested a projector based AR system for operators to easily identify the spots to check. They improved their system to also be used to improve the spot-welding quality during the manufacturing welding process (Doshi et al. 2017). Field experiments at an automotive plant showed at least a $15 \%$ increase in precision. Thus, the distance between the real weld-spot and the optimum position decreased when using the AR system. Antonelli and Astanin (2015) used a similar technique to increase the accuracy and quality of manual spot welding in the process by indicating the correct position of the.

\section{Logistics}

The percentage of documents in the logistics field is with $13 \%$ relatively low compared to the other fields within the time-frame from 2011 to 2018 (see Fig 7). However, logistics is an important field that can contribute to the maturity of the AR technology. An indication of this notion is the involvement of companies already providing commercial AR solutions for logistics in the research process (Guo et al. 2014). The most labour-intensive task in warehousing and logistics is the picking process (Tompkins 2010). A broad variety of AR 'pick-by-vision' systems are already commercially available (e.g. the 
solutions used by Guo et al. (2014)). After a brief review of literature prior to the period in question (2011-2018) showed that the picking process had already extensively been researched, especially a research group at the Technical University Munich (TUM) was active in this field (Günthner et al. 2009; Reif et al; Reif and Günthner 2009; Reif and Walch 2008).

Despite the maturity, use of AR systems in warehousing and especially picking is still an active research area, especially as intralogistics can complex, as described in (Liu and Ma et al. 2017). In complex cases AR might be beneficial. A tendency can be observed towards more specialised research around the topic, e.g. focusing on the transparency of HMDs (Guo et al. 2015). Murauer et al. (2018) analysed at BMW different scan methods for AR picking solutions to confirm if the right item was picked. This pilot project close to real-life intelligent manufacturing applications showed that the scanning technology itself had a significant impact if the benefits of AR unfolded. Stoltz et al. (2017) also had a similar conclusion concerning the scanning speed. Hanson et al. (2017) looked into a special application of order picking, namely kit preparation for mixed-model assembly. While being similar to warehouse picking, the picks for kit preparation occur in shorter time intervals (Maurizio Faccio et al. 2015). Results show that AR systems can also be superior to paper-based systems for this application.

Other logistics operations can also benefit from AR. Sarupuri et al. (2016) used a forklift model to determine if AR enhanced imagery from the already built-in cameras could have helped the operators in performing tasks in high-racking storages. AR proved to be superior concerning completion time and the error rate. Similar to the majority of assembly related experiments, the participants were not trained operators. These results could change when testing the system in the field.

The Fraunhofer Institute for Material Flow and Logistics in Dortmund, Germany, looks into different areas of internal logistics where AR could be utilised as well. Notable examples are palletisation and packaging. Within the experimental setup of Kretschmer et al. (2018), palletisation efficiency does not profit significantly from the use of AR. For the process of packaging items, however, AR can significantly increase the packaging speed and also in the utilisation of packaging space (Mättig et al. 2016).

\section{others}

The two main areas of application summarised in this section are SCADA tasks and machine set-up tasks supported by AR. Within a manufacturing environment, SCADA tasks can be enhanced through AR to, e.g. show real-time virtual copies and simulations (Lechevalier et al. 2017) of the physical system (Soete et al. 2015), or to preview the outcome of a machining operation during the process (Novak-Marcincin et al. 2014) and display relevant production data live on the factory floor (Rechowicz and Garcia 2016).

Liu and Cao et al. (2017) used AR to simulate and monitor the process by utilising real-time information from a milling machine. The AR framework developed by Ragni et al. (2018) supported the development of touching probes in manufacturing machines. They determine the exact position of a workpiece to prevent fatal collisions during machining. Their tool allowed for on-the-fly generation and simulation of probe trajectories with the aim of reducing set-up times.

Yew et al. (2016) went a step further and utilised AR as an intuitive online way to interact with a CPPS. Their solution not only showed process information, but allowed for interaction with a milling machine directly, replacing computer and paper-based tasks. The physical objects within their CPPS are completely replaceable with digital objects through AR.

\section{Challenges}

This section attempts to answer the second research question of this literature review (Q2: What are the current challenges that hinders the adoption of $A R$ in manufacturing?). The challenges mentioned in the documents are classified according to a hierarchical structure. Fig 11 displays the structure and the results. The white rectangles show the number of papers that mentioned an issue that falls in a certain section of classification. It is obvious, that the technology and especially the software are still amongst the main current challenges.

Based on the data extraction from the survey, it was obvious that field experiments are not often conducted compared to laboratory experiments (see Fig 9). As discussed above, field experiments lead to new insights into the challenges faced when implementing $A R$ solutions in the industry. From the conflicting results between laboratory and field experiments, it is obvious that those two scenarios are only comparable to a limited extent. Typically, new issues arose when AR systems were tested in industrial contexts. The current challenges ware rooted in that development. In order to analyse the field experiments in detail, a table has been compiled with detailed information on the experiment, the results, and identified challenges (see Table 5). The following sections show, where applicable, new challenges that were brought to light due to field experiments compared to the challenges encountered in laboratory experiments. 


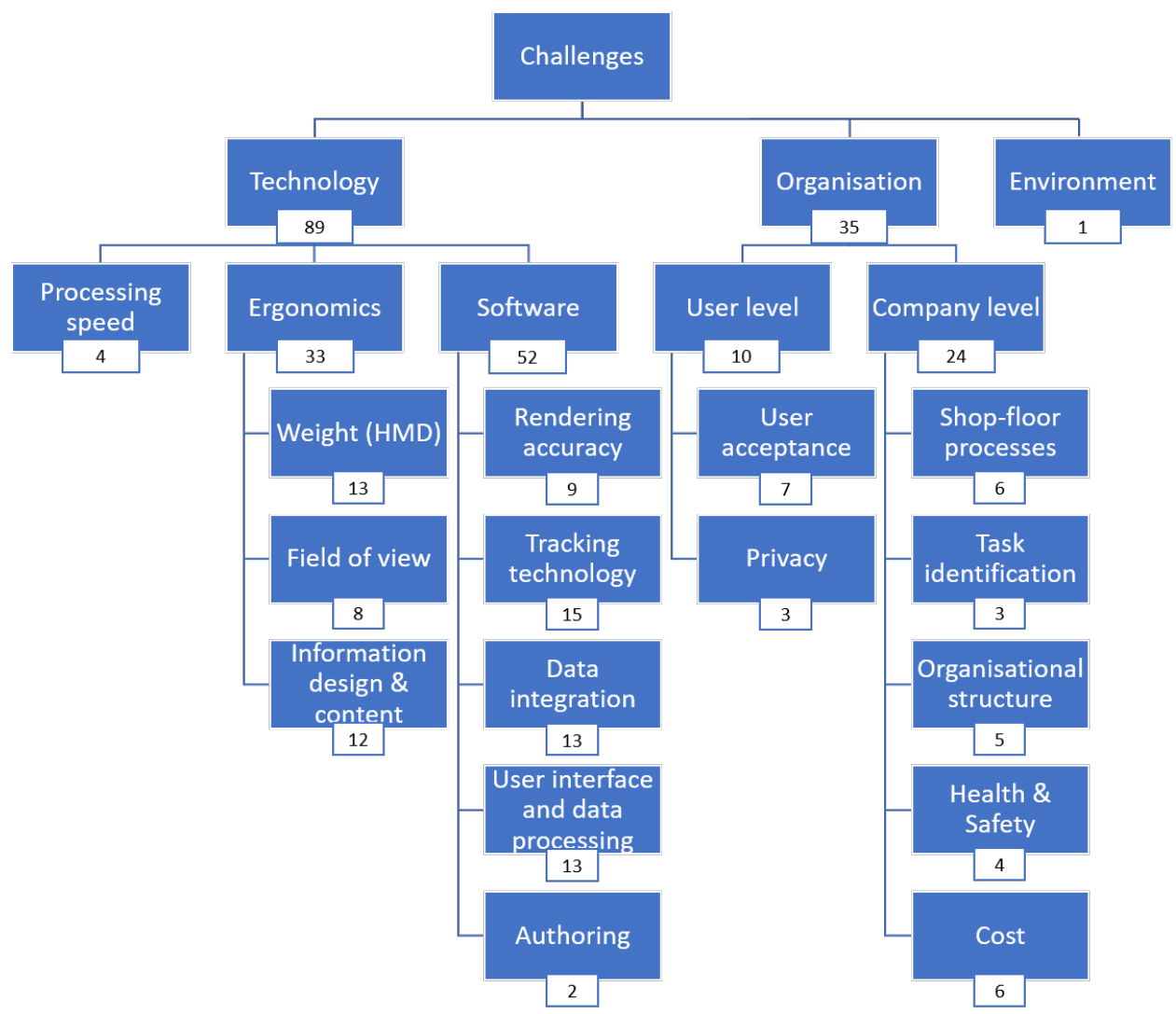

Fig 11 The hierarchical classification structure of current challenges shows the number of documents that mention such an issue

\section{Technology}

Despite the growing maturity of AR systems, most of the challenges were still classified as technological issues.

\section{Processing speed}

The processing speed of the hardware has improved over the years, as the processing power of microprocessors follows Moore's law (Moore 1965), which states that the density of transistors on integrated circuits doubles approximately every two years. This increase in processing power facilitates wearable and mobile solutions. A study done by Real and Marcelino (2011) still utilised laptops to provide the processing power for recognising markers and barcodes and for providing the digital content. The usability of that system prohibited adoption. Such a problem does not seem to be as pressing when using marker tracking technology. When using marker-less technology, the in-built processing power of HMDs was still an issue compared to HHDs. Marker-less tracking technology already was able to run in real-time on HHDs in certain applications (Wang et al. 2018).

\section{Ergonomics}

The usability of the systems was often a dependent variable of AR studies. The ergonomic design of an AR system is connected to user acceptance. It is still restricted by technological challenges. Before conducting (long-term) studies in industrial settings, the weight of
HMDs and the field of view was often criticised (Holm et al. 2017; Schlagowski et al. 2017; Makris et al. 2016; Maly et al. 2016; Mura et al. 2016). Yet, ergonomics is not limited to the wear-ability of HMDs, but also on how ergonomic the user interface is. It has been shown that long-term usage of AR systems in industrial settings can lead to visual fatigue (especially when using HMD) and impact concentration performance levels (Murauer et al. 2018). Despite the fact that AR can reduce head and neck movements during operations, e.g. maintenance operations (Henderson and Feiner 2011), workers can be distracted or disoriented by the information displayed itself (Funk et al. 2017; Hou et al. 2013). Doshi et al. (2017) found that the design of visual cues itself could change the performance impact of the AR system. Also, how to use icons instead of textual information was one of the current challenges (Hahn et al. 2015). 


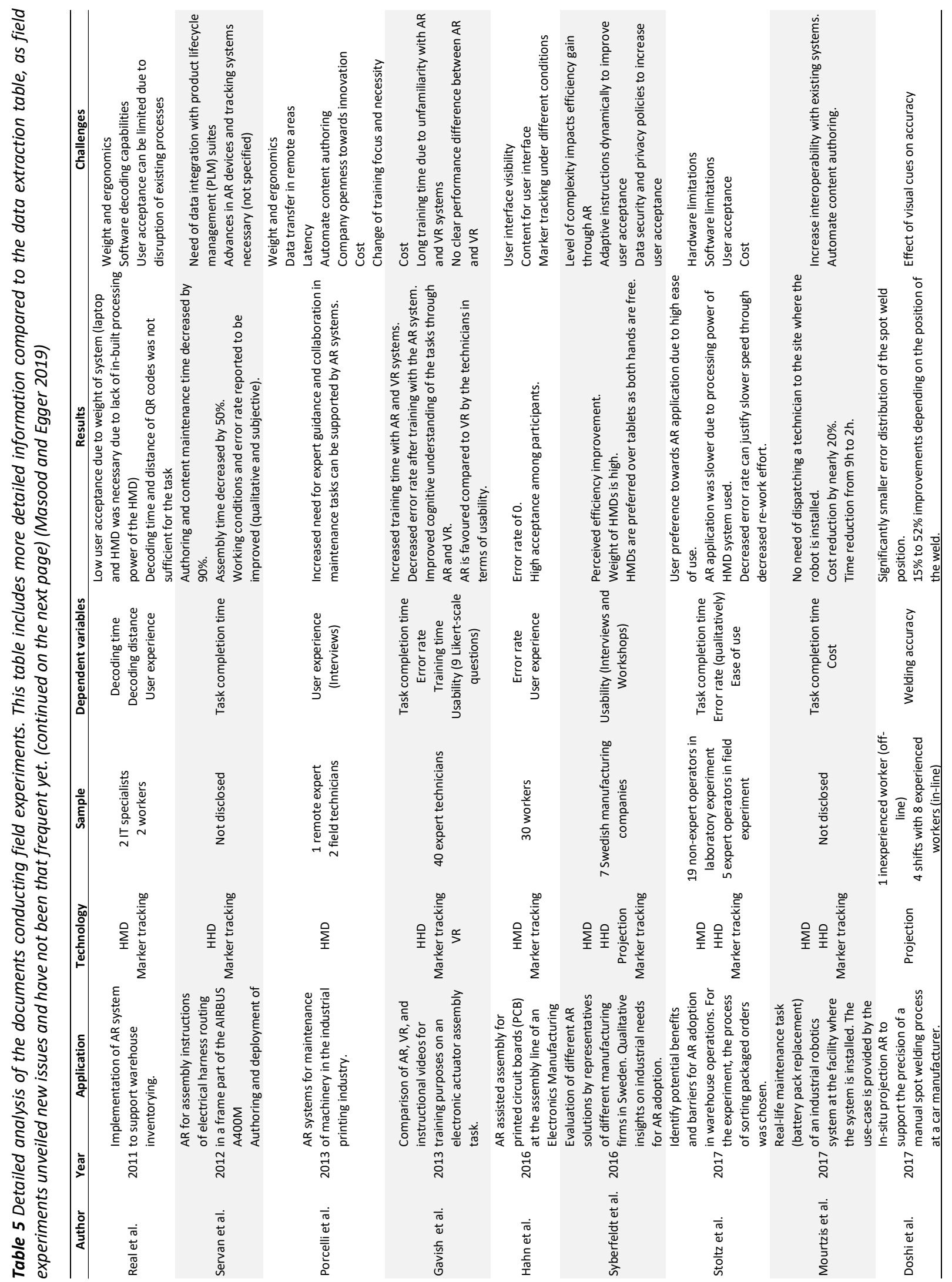




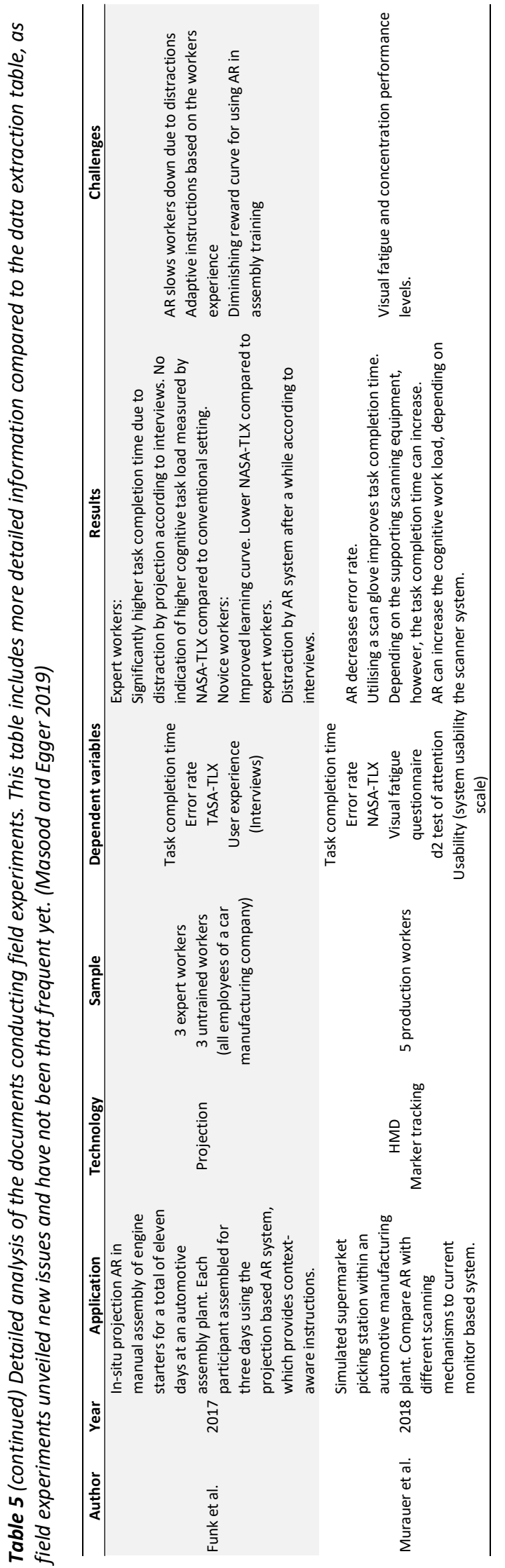

Software

The most common issues were software related. Especially the tracking technology in different circumstances was still a research focus (Blanco-Novoa et al. 2018; Kretschmer et al. 2018; Tong et al. 2016). As the technology matures, it becomes inherently important to be able to integrate AR solutions with the current information technology systems, for example, to visualise shop floor management information (Qian et al. 2017). Several studies focussed on that problem (Flatt et al. 2015; Havard et al. 2015; Serván et al. 2012) or acknowledged it (Mourtzis and Vlachou et al. 2017; Soete et al. 2015; Espíndola and Pereira et al. 2013). However, this is part of a bigger issue. As industrial systems become digitally enabled, the standardisation of modelling, interfaces, and data structures needs to follow certain standards, like UML, or OPC UA (Flatt et al. 2015; Havard et al. 2015) in order to facilitate intelligent manufacturing systems. It is not clear yet which selection out of the vast number of standards (Trappey et al. 2017) will be the dominant one for a certain task. This challenge cannot be tackled within the AR research community but needs a broader approach.

The user feedback often used some kind of hardware. In AR user interfaces there is no common framework on how the user can give the system feedback intuitively. Different studies on gesture recognition use different hand-gestures for controlling the system (Saxen et al. 2017; Wang et al. 2016; Rodriguez et al. 2015; Radkowski and Stritzke 2012; Radkowski and Stritzke 2012). To improve the familiarity with such systems, a common way of using hand gestures to interact with the systems is imperative.

\section{Organisation}

Especially when thinking about implementing AR, longterm and organisational effects need to be considered as well. This section describes challenges from a user perspective and from an organisational perspective.

User level

While being discussed more detailed aspects of user acceptance in the ergonomics section, it was an overarching topic in the field, but also in laboratory experiments. A sensitive issue arising from surveys amongst trial users was privacy and its protection (Stoltz et al. 2017; Syberfeldt et al. 2016; Hou et al. 2015). The challenge is based on the fact that indoor localisation (Flatt et al. 2015) and task/error tracking (Wolfartsberger et al. 2017) are inherently important for the performance of such a system. That opens users up to increased surveillance from superiors. A workshop based study by Syberfeldt et al. (2016) identified solutions to such issues of significance to successfully gain user acceptance.

\section{Company level}

The identified challenges in this category originated nearly exclusively in field experiments, as it was hard to detect challenges connected to the company where the technology is deployed in a laboratory setting. It was

Masood, T. and Egger, J. (2019) 'Augmented reality in support of intelligent manufacturing - A systematic literature review', Computers \& Industrial Engineering, accepted 18 November 2019.

Page | 21 
already shown that the experience of workers and the human factor, in general, is important concerning the acceptance of the technology. The organisation itself needs to be looked into.

No study reviewed in this article has researched if and how shop-floor operations and processes need to be adapted to allow AR to employ its full potential. Yet, the possible disruption or incompatibility was mentioned in some instances where AR was tested in industrial settings (Funk et al. 2017; Espíndola and Fumagalli et al. 2013; Espíndola and Pereira et al. 2013; Garza et al. 2013; Gavish et al. 2013; Porcelli et al. 2013; Real and Marcelino 2011). Not every task is suitable for being supported by AR solutions. It was indicated that an increasing level of task complexity might correlate to the benefit provided by AR (Blattgerste et al. 2017; Syberfeldt et al. 2016; Gavish et al. 2013). It was not clear which kind of tasks could profit from AR solutions, as some of the field studies revealed a negative performance influence when utilising AR (Funk et al. 2017; Gavish et al. 2013). Yet, it has to be noted, that this effect could be attributed to other issues as well, like unfamiliarity (Gavish et al. 2013), nonadaptive instructions (Funk et al. 2017), or user acceptance in general (Stoltz et al. 2017). Additional challenges on a company level included the organisational structure in general, health and safety concerns (Murauer et al. 2018; Makris et al. 2016) e.g. due to distraction, and cost / profitability implications (Stoltz et al. 2017; Hou et al. 2015; Espíndola and Pereira et al. 2013; Gavish et al. 2013; Porcelli et al. 2013; Bondrea and Petruse 2012).

\section{Environment}

The environment of a company adopting and implementing AR might play a role in how the technology is used as well. Those challenges can include the information integration of third parties, the regulatory environment concerning employment protection, the industry-wide standardisation of AR solutions, or the necessity of external support. However, no research has been conducted into that area. Only the aspect of necessary external support was mentioned (Stoltz et al. 2017).

\section{Future directions}

In this section, the future directions of research are proposed to answer the second research question (Q3: What are future directions of manufacturing related $A R$ research?). These directions are classified based on the challenges uncovered in the following areas:
1. Processing Speed
2. Ergonomics
3. Software
4. User level
5. Company level
6. Environment

Table 6 lists the uncovered future directions with more detailed suggestions for future research directions. It also highlights which of those research directions is summarised from the reviewed studies and which ones are identified by the authors of this study. Those points are common among the different areas of applications and are discussed in more detail in the following sections.

Table 6 Suggestions of likely future research directions based on the current challenges and the reviewed studies

\begin{tabular}{|c|c|c|c|}
\hline Area of Challenge & Future Direction & Detailed Suggestions & Source \\
\hline Processing Speed & Increase processing speed & - & Analysis of Q2/Q3 related articles \\
\hline \multirow{3}{*}{ Ergonomics } & \multirow{3}{*}{ Improve ergonomics } & Improve wearability through weight decrease & Analysis of $Q 2 / Q 3$ related articles \\
\hline & & Improve visibility of information through increased resolution and light intensity & Analysis of Q2/Q3 related articles \\
\hline & & Develop user interfaces to counteract visual fatigue & Analysis of Q2/Q3 related articles \\
\hline \multirow{4}{*}{ Software } & \multirow{4}{*}{$\begin{array}{l}\text { Improve softwar technology to } \\
\text { support users and implementation }\end{array}$} & Improve marker recognition & Analysis of $Q_{2} / Q_{3}$ related articles \\
\hline & & Data exchange and software integration & Analysis of $\mathrm{Q} 2 / \mathrm{Q} 3$ related articles \\
\hline & & Develop intuitive authoring solutions & Analysis of Q2/Q3 related articles \\
\hline & & Develop solutions for adaptive content based on the process or user experience & Analysis of $\mathrm{Q}_{2} / \mathrm{Q} 3$ related articles \\
\hline \multirow{2}{*}{ End-User level } & \multirow{2}{*}{ Improve end-user acceptance } & Investigate factors influencing end-user acceptance & Newly identified \\
\hline & & Determine measures to ensure privacy & Analysis of $Q_{2} / Q_{3}$ related articles \\
\hline \multirow{4}{*}{ Company level } & \multirow{4}{*}{$\begin{array}{l}\text { Research into challenges of } \\
\text { organisational implementation }\end{array}$} & Investigation of possible effects of AR systems on existing processes & Newly identified \\
\hline & & Investigation of possible effects of AR systems on the organisational strucutre & Newly identified \\
\hline & & Develop a framework to identify tasks suitable to be supported by AR systems & Newly identified \\
\hline & & Investigation of possible health and safety concerns & Analysis of Q2/Q3 related articles \\
\hline Environment & $\begin{array}{l}\text { Impact of the environment of the } \\
\text { organisation on AR implementation }\end{array}$ & $\begin{array}{l}\text { Determine factors attributed to the environment of the company that have an effect } \\
\text { on AR adoption and implementation }\end{array}$ & Newly identified \\
\hline
\end{tabular}

Processing Speed

In the future, processing power will have to increase, as marker-less tracking solutions are starting to be used. Those solutions consume significantly more computing resources compared to marker-based systems. Especially stand-alone HMDs suffer from a lack of processing speed due to special and weight restrictions imposed by the wear-ability of such devices. Increasing miniaturisation is necessary to provide ergonomic wearability and the necessary processing speed.

\section{Ergonomics}

Fig 8 shows the most prominent visualisation technologies used within AR. HMDs are prominently used due to their characteristic of being 'hands-free'. In general, the ergonomics have to be improved. The systems are still fairly heavy, and in several user surveys, the weight was a limiting factor for long-time usage of the device (Soete et al. 2015; Porcelli et al. 2013; Zhu et al. 2012). Those issues need to be resolved. In addition, the content visibility needs to be improved as well. The field 
of view is limited, prohibiting to extend the amount of information overlaid at a certain point.

When working with AR HMDs on a regular basis and throughout the day, visual fatigue is an identified issue (Murauer et al. 2018). Eye movement and the focus change between the user interface and the physical world can lead to visual fatigue. Currently, this effect is seldom measured. Measuring the extent of eye movement and visual fatigue after using HMDs for an extended period of time can provide information on how to improve the design of user interfaces (Aini and Arshad 2013).

\section{Software}

Even though marker-based tracking is the most widely used solution, improvements need to be made concerning its robustness and reliability (Kretschmer et al. 2018). While the number of markers necessary to reliably place objects has improved, the influence of the environment on the reliability is still an issue. The lighting conditions influence how well markers are recognised. In addition, in industrial environments dust or dirt can block the marker (Blanco-Novoa et al. 2018). Improved algorithms to detect and read markers can counteract those challenges in the future.

Natural markers within buildings have been proposed as a solution for such a problem but are not widespread in research. While marker-less tracking has the advantage that no markers need to be placed within the area the system is used, it was still in an early stage of (Radkowski and Stritzke 2012); (Real and Marcelino 2011); (Han and Zhao 2017; Wu and Wang 2011). Future research can focus on the new possibilities in manufacturing applications due to recent technological advancements.

As AR is moving towards real-life applications, the adaptability of the content is an important part and has two different perspectives to it. The first one is the adaptability towards the individual experience of the operator (Funk et al. 2017; Holm et al. 2017). Future research in that area could detect other parameters which indicate the experience of operators.

For widespread adoption, AR systems need to be integrated seamlessly into the existing IT infrastructure (Aini and Arshad 2013). To do so, standardised data exchange protocols need to be used (Zhou et al. 2017) and the solutions need to be flexible to be adapted for different needs (Kollatsch et al. 2014). Future research can focus on how to integrate AR systems solutions like predictive maintenance based on big data analysis (Schlagowski et al. 2017).

As laid out previously, implementing an AR solution in real-world environments brings new challenges. When looking into human-robot collaboration, the safety has to be improved. It has been pointed out that only visualising the safety areas around a robot might not be enough to ensure the safety of operators (Makris et al. 2016; Michalos et al. 2016). These systems need to integrate with detection systems and path planning algorithms to detect humans within the calculated path of the robot arm and to execute countermeasures.

The benefits provided by AR systems could be improved by developing easy content authoring systems that allow for content creation on both ends of the system. Operators need easy methods to author content while on the field. Currently, it is unclear to what extent such solutions are feasible using HMDs or when HHDs or stationary solutions should be preferred for content creation.

Another aspect that was not covered in the studies analysed is the adaptability concerning the operations itself. The experimental tasks were repetitive. However, several authors state that the number of product variants increases (Holm et al. 2017; Funk, Kosch and Schmidt 2016). This could that the number of different assembly operations a worker has to execute increases. The content displayed, especially for assembly tasks, needs to accommodate these changes. While this has been not dealt with yet, integrating AR systems in a broader data infrastructure is the goal of different research initiatives (Schlagowski et al. 2017; Porcelli et al. 2013). Future research can tackle this issue by developing systems that utilise real-time data from intelligent manufacturing information systems.

\section{User level}

User acceptance is crucial when implementing new technologies. Current research focuses on the cognitive workload when using AR, mainly utilising the NASA TLX for measuring. Yet, other models might be of use for a more holistic picture of user acceptance. The technology acceptance model (TAM) (Davis 1985) could help in answering those questions. It has been used to determine the user acceptance of AR in a consumer setting (Huang and Liao 2015). Yet, no research utilising this model has been conducted in an industrial environment. Another approach is to use experiments with workers determining the usability of AR solutions to discuss possible ways of involvement of the workforce to increase the user acceptance.

One issue that is highlighted in current research is the concern of privacy when using AR in the workplace. While the regulatory framework of each country obviously needs to be adhered to, it is unclear which measures would counteract the privacy concerns from a user perspective.

\section{Company level}

In general, the organisational challenges when adopting AR solutions need to be investigated. We propose that implementing such technologies within an industrial environment needs to be looked at from a broader perspective. AR does change work processes, the organisational hierarchy, and the whole information exchange process. This can have profound consequences 
for organisations, which have not been looked into yet in detail. Those changes affect the firm as a whole, but also operators on an individual level. Additionally, the company culture is affected. Stoltz et al. (2017) put it as follows: '... an important issue is a change in the existing mindset of both warehouse managers and operators who need to accept the new technology.' Future research can utilise technology adoption and implementation frameworks to explain the factors influencing the success of those implementation processes.AR was mainly applied in order to support existing processes by studies included in this review. However, it is possible that AR can only unfold its potential when altering the process and adapting it. For example, the work organisation process might become much more flexible through a significantly steeper learning curve of workers. This would also have implications for the organisational structure which need to be analysed.

The complexity of a task seems to correlate with the benefit AR can provide (Blattgerste et al. 2017; Syberfeldt et al. 2016; Gavish et al. 2013). Future research can focus on how to classify tasks based on their complexity and analyse the impact of AR systems on tasks with a different level of complexity. Some factors have already been used to determine where AR can provide a substantial benefit (Pantoja et al. 2014). However, it is not clear if those factors are representative and adequate. Thus, indicators, where AR would significantly improve performance, can be developed based on case studies in industry.

Industrial environments may be exposed to potential dangers. Using AR might have effects on the safety of the users. They could get distracted or plainly not see certain physical dangers. Research has to be conducted on how to ensure the safety of operators using AR.

\section{Environment}

The environment of the company has an effect on the adoption and implementation of technology (DePietro et al. 1990). Which factors attributed to the environment have an impact depends on the technology (Scupola 2014; Wang et al. 2010; Zhu et al. 2010; Kumar et al.) in the end and need to be taken into consideration. Currently, it is unclear what situation AR faces in that regard. Future research can build on previous research for other technologies and further develop it to also include AR systems.

\section{Conclusion}

The following main contributions of this paper are based on the literature review, which has answered the three questions within the context of $A R$ in support of intelligent manufacturing.

Contribution 1: First major contribution of this paper is the identification of the current status of manufacturing related $A R$ research (in response to Q1). Due to the systematic nature of the review we were able to provide a holistic view, not only focusing on an industry type or an application of the AR in manufacturing (see Table 1).

The citation network analysis highlighted active research areas and authors around the world. Three distinct geographical research clusters were identified in Europe and Asia. The technologies used and the current research focuses were outlined. From this current status, the industry can draw inspiration for industrial applications, as solutions applicable to industry as well as research in laboratories were reviewed.

While AR is not ready yet for industrial deployment in some areas, it is already used in others. Companies are testing and implementing AR solutions for different applications. The benefits shown for already implemented logistics solutions can also be (partially) applicable to other fields. The authors firmly believe that within a few years AR will be widespread among a broad variety of applications, especially as a growing proportion of research is conducted by or in cooperation with companies. Some of those experiments still showed mixed results concerning the performance. However, the potential benefits of AR shown through a broad variety of experiments incentivise to overcome those barriers.

Contribution 2: Second major contribution of this paper is the identification of the current challenges that hinders the adoption of $A R$ in manufacturing (in response to Q2). Compared to other reviews (see Table 1), the context of challenges was seen broader. Hence, not only technological challenges but organisational challenges are also included.

The status of the AR research has advanced significantly in recent years. Field experiments highlighted new challenges and limitations, as the industrial implementation causes organisational and user acceptance issues. This is not only relevant for academia but also particularly for the industry. The analysis of the field experiments provides guidance concerning potentially problematic areas when implementing AR solutions. It can be used to determine which aspects need to be considered for such projects.

Academia and industry alike can obtain an overview of current challenges to determine if AR is usable for certain applications. While coming a long way, hardware and software still require improvements in certain areas. A classification of the challenges shows that most of them are still of technological nature. It has been identified, via the structured literature review presented in this paper, that hardware and software are still the main limitations of $A R$ and require further research. Especially the user interfaces and the user interactions prove to be among major issues. It is not clear yet how the users can intuitively interact with the technology.

Tasks to be supported by AR vary. These variations influence the effectiveness of AR systems. Additionally, this new technology needs to be the starting point of reengineering current processes to fit the technology. 
Through analysis of these possible challenges, this structured literature review has highlighted stepping stones for further research, which can alleviate those challenges and promote the implementation of $A R$ solutions in the industry of the future.

Contribution 3: Third major contribution of this paper is the identification of future directions of manufacturing related $A R$ research (in response to Q3). Similar to contribution 2, the broad perspective of this literature review enabled identification of future research directions not only focused on the technological but also the organisational side.

The future research needs to focus on intelligent manufacturing applications of AR based on the identified challenges and structured review of the recent research presented in this paper. Suggestions are made, that can inspire future $A R$ research in support of intelligent manufacturing. It is obvious that hardware advances will alleviate some of the problems concerning data processing and wear-ability. However, our findings show that it is necessary to be user-centric in future application development. Otherwise, the user acceptance could suffer hindering the efficiency of the technology itself. Since a significant proportion of the literature has examined the technological aspects of $A R$, future research needs to focus on the implementation of $A R$ in practice keeping in mind the intelligence requirements of the manufacturing industry of the future.

\section{Acknowledgements}

The authors are most grateful to the reviewers and colleagues for their constructive and helpful comments.

\section{References}

ABB AG. "YuMi." Accessed June 1, 2018. https://new.abb.com/future/yumi.

Aini, Abd Majid Nazatul, and Haslina Arshad. "Towards the Integration of Mobile Augmented Reality within an Aluminium Process Fault Detection and Diagnosis System." Advanced Materials Research 845 (2013):703-7.

Antonelli, Dario, and Sergey Astanin. "Enhancing the Quality of Manual Spot Welding through Augmented Reality Assisted Guidance." Procedia CIRP 33 (2015):556-561.

Aschenbrenner, Doris, Nicolas Maltry, and Johannes Kimmel et al. "ARTab - using Virtual and Augmented Reality Methods for an improved Situation Awareness for Telemaintenance" IFAC-PapersOnLine 49, 30 (2016):204-9.

Azuma, Ronald T. "A Survey of Augmented Reality." Presence: Teleoperators and Virtual Environments 6, 4 (1997):355-385.

Belhadi, Amine, Karim Zkik, Anass Cherrafi et al. "Understanding Big Data Analytics for Manufacturing Processes: Insights from Literature Review and Multiple Case Studies." Computers \& Industrial
Engineering

137

(2019),

https://doi.org/10.1016/j.cie.2019.106099.

Blanco-Novoa, Oscar, Tiago M. Fernandez-Carames, and Paula Fraga-Lamas et al. "A Practical Evaluation of Commercial Industrial Augmented Reality Systems in an Industry 4.0 Shipyard." IEEE Access 6 (2018):8201.

Blattgerste, Jonas, Benjamin Strenge, and Patrick Renner et al. "Comparing Conventional and Augmented Reality Instructions for Manual Assembly Tasks." In Proceedings of the 10th International Conference on Pervasive Technologies Related to Assistive Environments, 75-82. New York, NY. ACM 2017.

Bondrea, loan, and Radu Emanuil Petruse. "Augmented Reality - An Improvement for Computer Integrated Manufacturing." Advanced Materials Research 628 (2012):330-36.

Booth, Andrew, Anthea Sutton, and Diana Papaionnannou. Systematic approaches to a successful literature review. 2nd edition. Los Angeles, London, New Delhi, Singapore, Washington DC, Melbourne: Sage, 2016.

Bosch, Tim, Reinier Könemann, and Hans de Cock et al. "The effects of projected versus display instructions on productivity, quality and workload in a simulated assembly task." In Proceedings of the 10th International Conference on Pervasive Technologies Related to Assistive Environments, 412-415. New York, NY. ACM 2017.

Buchanan, David A. and Alan Bryman, eds. The Sage handbook of organizational research methods. Los Angeles: Sage, 2009.

Carmigniani, Julie, Borko Furht, and Marco Anisetti et al. "Augmented reality technologies, systems and applications." Multimedia Tools and Applications 51, 1 (2011):341-377.

Chang, Ren-Jung, and Jia-Cheng Jau. "Augmented Reality in Peg-in-Hole Microassembly Operations." International Journal of Automation Technology 10, 3 (2016):438-46.

Cheng, Jiangfeng, Weihai Chen, and Fei Tao et al. "Industrial IoT in 5G environment towards smart manufacturing." Journal of Industrial Information Integration 10 (2018):10-19.

Crescenzio, Francesca de, Massimiliano Fantini, and Franco Persiani et al. "Augmented reality for aircraft maintenance training and operations support." IEEE computer graphics and applications 31, 1 (2011):96101.

Curran, Kevin, Denis McFadden, and Ryan Devlin. "The Role of Augmented Reality within Ambient Intelligence." In Pervasive and Ubiquitous Technology Innovations for Ambient Intelligence Environments. Edited by Kevin Curran, 73-88. IGI Global 2013.

Davies, Ron. "Industry 4.0: Digitalisation for productivity and growth." European Parliamentary Research Service, 2015.

Davis, Fred D. "A Technology Acceptance Model for Empirically Testing New End-Uster Information Systems: Theory and Resulty." Ph.D. Thesis, Sloan 
School of Management, Massachusetts Institute of Technology, 1985.

Denyer, D., and D. Tranfield. "Producing a literature review." In The Sage handbook of organizational research methods. Edited by David A. Buchanan and Alan Bryman, 671-89. Los Angeles. Sage 2009.

DePietro, Rocoo, Edith Wiarda, and Mitchell Fleischer. "The context for change: Organization, technology and environment." In The processes of technological innovation. Edited by Louis G. Tornatzky and Mitchell Fleischer, 151-175. Issues in organization and management series. Lexington Mass. Lexington Books 1990.

Doshi, Ashish, Ross T. Smith, and Bruce H. Thomas et al. "Use of projector based augmented reality to improve manual spot-welding precision and accuracy for automotive manufacturing." The International Journal of Advanced Manufacturing Technology 89, 58 (2017):1279-93.

Engelke, Timo, Jens Keil, and Pavel Rojtberg et al. "Content First - A concept for Industrial Augmented Reality Maintenance Applications using Mobilde Devices." In Proceedings of the 6th ACM Multimedia Systems Conference. Edited by Wei T. Ooi, Wu-chi Feng and Feng Liu, 105-11. New York N.Y. ACM 2015.

Erkoyuncu, John Ahmet, Iñigo Fernández del Amo, and Michela Dalle Mura et al. "Improving efficiency of industrial maintenance with context aware adaptive authoring in augmented reality." CIRP Annals 66, 1 (2017):465-68.

Espíndola, Danúbia B., Carlos E. Pereira, and Eduardo Schneider et al. "Improving Maintenance Operations Through Application of Mixed Reality Systems." IFAC Proceedings Volumes 46, 7 (2013):11-16.

Espíndola, Danúbia Bueno, Luca Fumagalli, and Marco Garetti et al. "A model-based approach for data integration to improve maintenance management by mixed reality." Computers in Industry 64, 4 (2013):376-391.

Fiorentino, Michele, Antonio E. Uva, and Michele Gattullo et al. "Augmented reality on large screen for interactive maintenance instructions." Computers in Industry 65, 2 (2014):270-78.

Flatt, Holger, Nils Koch, and Carsten Rocker et al. "A context-aware assistance system for maintenance applications in smart factories based on augmented reality and indoor localization." In 2015 IEEE 20th Conference on Emerging Technologies \& Factory Automation (ETFA): 8 - 11 Sept. 2015, City of Luxembourg, Luxembourg, 1-4. Piscataway, NJ. IEEE 2015.

Forschungsunion, ed. Im Fokus: Das Zukunftsprojekt Industrie 4.0; Handlungsempfehlungen zur Umsetzung; Bericht der Promotorengruppe Kommunikation. 2012.

Fraga-Lamas, Paula, Tiago M. Fernandez-Carames, and Oscar Blanco-Novoa et al. "A Review on Industrial Augmented Reality Systems for the Industry 4.0 Shipyard." IEEE Access 6 (2018):13358-13375.
Franceschini, Fiorenzo, Maurizio Galetto, and Domenico Maisano et al. "Towards the use of augmented reality techniques for assisted acceptance sampling." Proceedings of the Institution of Mechanical Engineers, Part B: Journal of Engineering Manufacture 230, 10 (2016):1870-84.

Funk, Markus, Andreas Bächler, and Liane Bächler et al. "Working with Augmented Reality? A Long-Term Analysis of In-Situ Instructions at the Assembly Workplace." In Proceedings of the 10th International Conference on Pervasive Technologies Related to Assistive Environments, 222-229. New York, NY. ACM 2017.

Funk, Markus, Thomas Kosch, and Scott W. Greenwald et al. "A benchmark for interactive augmented reality instructions for assembly tasks." In Proceedings of the 14th International Conference on Mobile and Ubiquitous Multimedia. Edited by Clemens Holzmann and René Mayrhofer, 253-57. New York N.Y. ACM 2015.

Funk, Markus, Thomas Kosch, and Romina Kettner et al. "motionEAP: An Overview of 4 Years of Combining Industrial Assembly with Augmented Reality for Industry 4.0." In. Proceedings of the 16th international conference on knowledge technologies and data-driven business 2016.

Funk, Markus, Thomas Kosch, and Albrecht Schmidt. "Interactive worker assistance." In Proceedings of the 2016 ACM International Joint Conference on Pervasive and Ubiquitous Computing. Edited by Paul Lukowicz et al., 934-939. New York, NY. ACM 2016.

Garza, Luis Eduardo, Gabriel Pantoja, and Pablo Ramírez et al. "Augmented Reality Application for the Maintenance of a Flapper Valve of a Fuller-kynion Type M Pump." Procedia Computer Science 25 (2013):154-60.

Gavish, Nirit, Teresa Gutiérrez, and Sabine Webel et al. "Evaluating virtual reality and augmented reality training for industrial maintenance and assembly tasks." Interactive Learning Environments 23, 6 (2013):778-798.

Greenhalgh, Trisha, and Richard Peacock. "Effectiveness and efficiency of search methods in systematic reviews of complex evidence: Audit of primary sources." BMJ (Clinical research ed.) 331, 7524 (2005):1064-65.

Günthner, Willibald A., Niels Blomeyer, Rupert Reif, and Michael Schedlbauer. Pick-by-Vision: Augmented Reality unterstützte Kommissionierung. Garching: Lehrstuhl für Fördertechnik Materialfluß Logistik (fml) Techn. Univ. München, 2009.

Guo, Anhong, Thad Starner, and Shashank Raghu et al. "A comparison of order picking assisted by head-up display (HUD), cart-mounted display (CMD), light, and paper pick list." In Proceedings of the 2014 ACM International Symposium on Wearable Computers. Edited by Lucy Dunne, Tom Martin and Michael Beigl, 71-78. New York, NY. ACM 2014. 
Guo, Anhong, Xiaolong $\mathrm{Wu}$, and Zhengyang Shen et al. "Order Picking with Head-Up Displays." Computer 48, 6 (2015):16-24.

Hahn, Jürgen, Bernd Ludwig, and Christian Wolff. "Augmented reality-based training of the PCB assembly process." In Proceedings of the 14th International Conference on Mobile and Ubiquitous Multimedia. Edited by Clemens Holzmann and René Mayrhofer, 395-399. New York, NY. ACM 2015.

Hallward-Driemeier, Mary, and Gaurav Nayyar. Trouble in the making? The future of manufacturing-led development. Washington: World Bank Group, 2018.

Han, Pengfei, and Gang Zhao. "Line-based initialization method for mobile augmented reality in aircraft assembly." The Visual Computer 33, 9 (2017):118596.

Hanson, Robin, William Falkenström, and Mikael Miettinen. "Augmented reality as a means of conveying picking information in kit preparation for mixed-model assembly." Computers \& Industrial Engineering 113 (2017):570-575.

Hart, Sandra G., and Lowell E. Staveland. "Development of NASA-TLX (Task Load Index): Results of Empirical and Theoretical Research." In Human Mental Workload. Vol. 52, 139-83. Advances in Psychology. Elsevier 1988.

Havard, V., D. Baudry, and A. Louis et al. "Augmented reality maintenance demonstrator and associated modelling." In 2015 IEEE virtual reality (VR): 23 - 27 March 2015, Arles, France; [including papers from the] Workshop on Perceptual and Cognitive Issues in AR (PERCAR). Edited by Tobias Höllerer, 329-330. Piscataway, NJ. IEEE 2015.

Henderson, Steven, and Steven Feiner. "Exploring the benefits of augmented reality documentation for maintenance and repair." IEEE transactions on visualization and computer graphics 17, 10 (2011):1355-68.

Henderson, Steven J., and Steven K. Feiner. "Augmented reality in the psychomotor phase of a procedural task." In 10th IEEE International Symposium on Mixed and Augmented Reality (ISMAR), 2011: 26 - 29 Oct. 2011, Basel, Switzerland, 191-200. Piscataway, NJ. IEEE 2011.

Holm, Magnus, Oscar Danielsson, and Anna Syberfeldt et al. "Adaptive instructions to novice shop-floor operators using Augmented Reality." Journal of Industrial and Production Engineering 34, 5 (2017):362-374.

Hořejší, Petr. "Augmented Reality System for Virtual Training of Parts Assembly." Procedia Engineering 100 (2015):699-706.

Hou, Lei, and Xiangyu Wang. "A study on the benefits of augmented reality in retaining working memory in assembly tasks: A focus on differences in gender." Automation in Construction 32 (2013):38-45.

Hou, Lei, Xiangyu Wang, and Leonhard Bernold et al. "Using Animated Augmented Reality to Cognitively
Guide Assembly." Journal of Computing in Civil Engineering 27, 5 (2013):439-51.

Hou, Lei, Xiangyu Wang, and Martijn Truijens. "Using Augmented Reality to Facilitate Piping Assembly: An Experiment-Based Evaluation." Journal of Computing in Civil Engineering 29 (2015):1-12.

$\mathrm{Hu}$, Yifan. "Efficient, High-Quality Force-Directed Graph Drawing." The Mathematica Journal 10 (2006).

Huang, Tseng-Lung, and Shuling Liao. "A model of acceptance of augmented-reality interactive technology: The moderating role of cognitive innovativeness." Electronic Commerce Research 15, 2 (2015):269-95.

Jayaweera, Malith, Indika Wijesooriya, and Damith Wijewardana et al. "Enhanced Real-Time Machine Inspection with Mobile Augmented Reality for Maintenance and Repair." In Proceedings of the 2nd ACM/IEEE International Conference on Internet-ofTings Design and Implementation. Edited by Unknown, 287-88. New York, NY. ACM 2017.

Kagermann, Hanning, Wolfgang Wahlster, and Johannes Helbig. "Umsetzungsempfehlungen für das Zukuntsprojekt Industrie 4.0: Abschlussbericht des Arbeitskreises Industrie 4.0." BMBF, 2013. https://www.bmbf.de/files/Umsetzungsempfehlung en_Industrie4_0.pdf.

Kajikawa, Yuya, Junko Ohno, and Yoshiyuki Takeda et al. "Creating an academic landscape of sustainability science: An analysis of the citation network." Sustainability Science 2, 2 (2007):221-31.

Koch, Christian, Matthias Neges, and Markus König et al. "Natural markers for augmented reality-based indoor navigation and facility maintenance." Automation in Construction 48 (2014):18-30.

Kocisko, Marek, Monika Teliskova, and Petr Baron et al. "An integrated working environment using advanced augmented reality techniques." In 2017 4th International Conference on Industrial Engineering and Applications - ICIEA 2017: April 21-23, 2017, Nagoya, Japan, 279-83. Piscataway, NJ. IEEE 2017.

Kollatsch, Christian, Marco Schumann, and Philipp Klimant et al. "Mobile Augmented Reality Based Monitoring of Assembly Lines." Procedia CIRP 23 (2014):246-51.

Kong, Xiang T. R., Hao Luo, and George Q. Huang et al. "Industrial wearable system: The human-centric empowering technology in Industry 4.0." Journal of Intelligent Manufacturing 5, 3 (2018):351.

Kretschmer, V., T. Plewan, and G. Rinkenauer et al. "Smart palletisation: Cognitive ergonomics in augmented reality based palletising." In 1st International Conference on Intelligent Human Systems Integration: Integrating People and Intelligent Systems. Vol. 722, 355-360 2018.

KUKA AG. "LBR iiwa." Accessed June 1, 2018. https://www.kuka.com/en-de/products/robotsystems/industrial-robots/lbr-iiwa.

Kumar, Karripur N., Shalini Chandra, and Supreeth Bharati et al. "Factors influencing adoption of augmented

Masood, T. and Egger, J. (2019) 'Augmented reality in support of intelligent manufacturing - A systematic literature review', Computers \& 
reality technology for e-commerce." In PACIS proceedings 2016, 1-9.

Lamberti, Fabrizio, Federico Manuri, and Andrea Sanna et al. "Challenges, Opportunities, and Future Trends of Emerging Techniques for Augmented Reality-Based Maintenance." IEEE Transactions on Emerging Topics in Computing 2, 4 (2014):411-21.

Lamberti, Fabrizio, and Fernando Pescador. "Advanced Interaction and Virtual/Augmented Reality-Part II: A Look at Novel Applications." IEEE Consumer Electronics Magazine 7, 3 (2018):62-63.

Lambiotte, R., J. -C Delvenne, and M. Barahona. "Laplacian Dynamics and Multiscale Modular Structure in Networks." IEEE Transactions on Network Science and Engineering 1, 2 (2014):76-90.

Lechevalier, David, Seung-Jun Shin, and Sudarsan Rachuri et al. "Simulating a virtual machining model in an agent-based model for advanced analytics." Journal of Intelligent Manufacturing 19, 6 (2017): 699.

Lee, Sanghoon, and Ömer Akin. "Augmented realitybased computational fieldwork support for equipment operations and maintenance." Automation in Construction 20, 4 (2011):338-52.

Leutert, Florian, and Klaus Schilling. "Augmented Reality for Telemaintenance and -inspection in ForceSensitive Industrial Robot Applications." IFACPapersOnLine 48, 10 (2015):153-58.

$\mathrm{Li}$, Ling. "China's manufacturing locus in 2025: With a comparison of "Made-in-China 2025" and "Industry 4.0"' Technological Forecasting and Social Change 135 (2018):66-74.

Liu, Chao, Sheng Cao, and Wayne Tse et al. "Augmented Reality-assisted Intelligent Window for Cyber-Physical Machine Tools." Journal of Manufacturing Systems 44 (2017):280-86.

Liu, Mingzhou, Jing Ma, and Ling Lin et al. "Intelligent assembly system for mechanical products and key technology based on internet of things." Journal of Intelligent Manufacturing 28, 2 (2017):271-99.

Longo, Francesco, Letizia Nicoletti and Antonio Padovano. "Smart operators in Industry 4.0: A human-centred approach to enhance operators' capabilities and competencies within the new smart factory context." Computers \& Industrial Engineering 113 (2017):144159.

Majewski, Maciej, and Wjciech Kacalak. "Human-Machine Speech-Based Interfaces with Augmented Reality and Interactive Systems for Controlling Mobile Cranes." In Interactive Collaborative Robotics. Edited by Andrey Ronzhin, Gerhard Rigoll and Roman Meshcheryakov, 89-98. Cham. Springer International Publishing 2016.

Makris, Sotiris, Panagiotis Karagiannis, and Spyridon Koukas et al. "Augmented reality system for operator support in human-robot collaborative assembly." CIRP Annals 65, 1 (2016):61-64.

Malik, Ali Ahmad, Tariq Masood, and Arne Bilberg. "Virtual reality in manufacturing: Immersive and collaborative artificial-reality in design of humanrobot workspace." International Journal of Computer
Integrated Manufacturing (in press) Accepted for publication on 4 November 2019.

Maly, Ivo, David Sedlacek, and Paulo Leitao. "Augmented reality experiments with industrial robot in industry 4.0 environment." In Proceedings, 2016 IEEE 14th International Conference on Industrial Informatics (INDIN): Palais des Congrès du Futuroscope, Futuroscope - Poitiers, France, 19-21 July, 2016, 17681. Piscataway, NJ. IEEE 2016.

Martinetti, Alberto, Mohammad Rajabalinejad, and Leo van Dongen. "Shaping the Future Maintenance Operations: Reflections on the Adoptions of Augmented Reality Through Problems and Opportunities." Procedia CIRP 59 (2017):14-17.

Masoni, Riccardo, Francesco Ferrise, and Monica Bordegoni et al. "Supporting Remote Maintenance in Industry 4.0 through Augmented Reality." Procedia Manufacturing 11 (2017):1296-1302.

Masood, Tariq, and Johannes Egger. "Augmented reality in support of Industry 4.0: Implementation challenges and success factors." Robotics and Computer Integrated Manufacturing 58 (2019):181-195.

Masood, Tariq, and Johannes Egger. "Adopting augmented reality in the age of industrial digitalisation." Computers in Industry (in press) Accepted for publication on 9 July 2019.

Masood, Tariq, Johannes Egger, and Maximilian Kern. "Future-proofing the Through-life Engineering Service Systems." Procedia Manufacturing 16 (2018):179-86.

Mättig, Benedikt, Isabel Lorimer, and Jana Jost et al. "Untersuchung des Einsatzes von Augmented Reality im Verpackungsprozess unter Berücksichtigung spezifischer Anforderungen an die Informationsdarstellung sowie die ergonomische Einbindung des Menschen in den Prozess." 2016.

Maurizio Faccio, Yuval Cohen, Robin Hanson, and Lars Medbo et al. "Order batching and time efficiency in kit preparation." Assembly Automation 35, 1 (2015):143-48.

Michalos, George, Panagiotis Karagiannis, and Sotiris Makris et al. "Augmented Reality (AR) Applications for Supporting Human-robot Interactive Cooperation." Procedia CIRP 41 (2016):370-75.

Milgram, Paul, Karuo Takemura, and Akira Utsumi et al. "Augmented Reality: A class of displays on the realityvirtuality continuum." Telemanipulator and Telepresence Technologies, 2351 (1994):282-2802.

Moore, Gordon E. "Cramming more components onto integrated circuits." Electronics 38, 8 (1965).

Mourtzis, D., V. Zogopoulos, and E. Vlachou. "Augmented Reality Application to Support Remote Maintenance as a Service in the Robotics Industry." Procedia CIRP 63 (2017):46-51.

Mourtzis, Dimitris, Aikaterini Vlachou, and Vasilios Zogopoulos. "Cloud-Based Augmented Reality Remote Maintenance Through Shop-Floor Monitoring: A Product-Service System Approach." Journal of Manufacturing Science and Engineering 139, 6 (2017):1-11. 
Mura, Michela Dalle, Gino Dini, and Franco Failli. "An Integrated Environment Based on Augmented Reality and Sensing Device for Manual Assembly Workstations." Procedia CIRP 41 (2016):340-45.

Murauer, Nela, Nerina Pflanz, and Cecilia von Hassel. "Comparison of Scan-Mechanisms in Augmented Reality-Supported Order Picking Processes." CEUR Workshop Proceedings 2082 (2018):69-76.

Nee, A.Y.C., and S. K. Ong. "Virtual and Augmented Reality Applications in Manufacturing." IFAC Proceedings Volumes 46, 9 (2013):15-26.

Nee, A.Y.C., S. K. Ong, and G. Chryssolouris et al. "Augmented reality applications in design and manufacturing." CIRP Annals 61, 2 (2012):657-79.

Novak-Marcincin, J., J. Barna, and M. Janak et al. "Visualization of intelligent assembling process by augmented reality tools application." In 2012 4th IEEE International Symposium on Logistics and Industrial Informatics (LINDI): 5 - 7 Sept. 2012, Smolenice, Slovakia, 33-36. Piscataway, NJ. IEEE 2012.

Novak-Marcincin, Jozef, Patrik Szentivanyi, and Miroslav Janak et al. "Diagnostic of Manufacturing Devices Operational States by Smart-Phones Application with Use of Augmented Reality Methods." Applied Mechanics and Materials 616 (2014):3-10.

Oztemel, Ercan, and Samet Gursev. "Literature review of Industry 4.0 and related technologies." Journal of Intelligent Manufacturing 47, 4 (2018):3.

Pacaux-Lemoine, Marie-Pierre, Damien Trentesaux, Gabriel Zambrano et al. "Designing intelligent manufacturing systems through Human-Machien Cooperation principles: A human-centred approach." Computers \& Industrial Engineering 111 (2017):581595.

Paelke, Volker. "Augmented reality in the smart factory: Supporting workers in an industry 4.0. environment." In IEEE [International Conference on] Emerging Technologies and Factory Automation (ETFA), 2014: 16 - 19 Sept. 2014, Barcelona, Spain, 1-4. Piscataway, NJ. IEEE 2014.

Paelke, Volker, and Carsten Röcker. "User Interfaces for Cyber-Physical Systems: Challenges and Possible Approaches." In Design, User Experience, and Usability: Design Discourse. Vol. 9186. Edited by Aaron Marcus, 75-85. Lecture Notes in Computer Science. Cham. Springer International Publishing 2015.

Pai, Yun Suen, Hwa Jen Yap, and Ramesh Singh. "Augmented reality-based programming, planning and simulation of a robotic work cell." Proceedings of the Institution of Mechanical Engineers, Part B: Journal of Engineering Manufacture 229, 6 (2014):1029-45.

Palmarini, Riccardo, John Ahmet Erkoyuncu, and Rajkumar Roy. "An Innovative Process to Select Augmented Reality (AR) Technology for Maintenance." Procedia CIRP 59 (2017):23-28.

Palmarini, Riccardo, John Ahmet Erkoyuncu, and Rajkumar Roy et al. "A systematic review of augmented reality applications in maintenance." Robotics and Computer-Integrated Manufacturing 49 (2018):215-28.

Pantoja, Gabriel, Luis Eduardo Garza, and Eduardo Gonzalez Mendivil. "Augmented reality in pneumatic conveying system: Fuller pump dry material line charger." In 9th Iberian Conference on Information Systems and Technologies (CISTI), 2014: 18 - 21 June 2014, Barcelona, Spain; [including workshops]. Edited by Álvaro Rocha, 1-5. Piscataway, NJ. IEEE 2014.

Park, Hyung M., Seok H. Lee, and Jong S. Choi. "Wearable Augmented Reality System using Gaze Interaction." In 7th IEEE/ACM International Symposium on Mixed and Augmented Reality, 2008: ISMAR 2008; Sept. 15 - 18, 2008, Cambridge, UK. Edited by Mark A. Livingston, 175-176. Piscataway, NJ. IEEE Service Center 2008.

Peruzzini, Margherita, Fabio Grandi and Marcello Pellicciari. "Exploring the potential of Operator 4.0 interface and monitoring." Computers \& Industrial Engineering (in press) Accepted for publication on 19 December, 2018, https://doi.org/10.1016/j.cie.2018.12.047.

Porcelli, Isabella, Mario Rapaccini, and Danúbia B. Espíndola et al. "Technical and Organizational Issues about the Introduction of Augmented Reality in Maintenance and Technical Assistance Services." IFAC Proceedings Volumes 46, 7 (2013):257-262.

Qian, Xiaoming, Jiachen Tu, and Peihuang Lou. "A general architecture of a 3D visualization system for shop floor management." Journal of Intelligent Manufacturing 26, 2 (2017):377.

Radkowski, Rafael, and Christian Stritzke. "Interactive Hand Gesture-based Assembly for Augmented Reality Applications." In ACHI 2012: The Fifth International Conference on Advances in Computer-Human Interactions January 30-February 4, 2012, Valencia, Spain. Edited by Leslie Miller and Silvana Roncagliolo, 303-8. Wilmington, DE, USA. IARIA 2012.

Ragni, Matteo, Matteo Perini, and Amedeo Setti et al. "ARTool Zero: Programming trajectory of touching probes using augmented reality." Computers \& Industrial Engineering 124 (2018):462-73.

Real, Joao, and Luis Marcelino. "Augmented Reality Systems for Inventorying." In 6th Iberian Conference on Information Systems and Technologies (CISTI), 2011: 15 - 18 June 2011, Chaves, Portugal; [including workshop papers]. Edited by Álvaro Rocha, 1-9. Piscataway, NJ. IEEE 2011.

Rechowicz, Krzysztof J., and Hector Garcia. "Process Driven Framework for Autmented Reality in A Manufacturing Environment." In Proceedings of the 15th International Conference on Modeling and Applied Simulation. Edited by Agostino G. Bruzzone et al., 65-72 2016.

Reif, Rupert, Willibald A. Guenther, and Bjoern Schwerdtfeger et al. "Pick-by-vision comes of Age: Evaluation of an augmented reality supported picking system in real storage environment." In Proceedings of the 6th International Conference on Computer 
Graphics, Virtual Reality, Visualisation and Interaction. Edited by Alexandre Hardy et al., 23-32. New York, NY. ACM 2009.

Reif, Rupert, and Willibald A. Günthner. "Pick-by-vision: Augmented reality supported order picking." The Visual Computer 25, 5-7 (2009):461-467.

Reif, Rupert, and Dennis Walch. "Augmented \& Virtual Reality applications in the field of logistics." The Visual Computer 24, 11 (2008):987-94.

Renner, Patrick, and Thies Pfeiffer. "Augmented Reality Assistance in the Central Field-of-View Outperforms Peripheral Displays for Order Picking: Results from a Virtual Reality Simulation Study." In 2017 IEEE International Symposium on Mixed and Augmented Reality (ISMAR-Adjunct), 176-181 2017.

Renner, Patrick, and Thies Pfeiffer. "Evaluation of Attention Guiding Techniques for Augmented Realitybased Assistance in Picking and Assembly Tasks." In Proceedings of the 22nd International Conference on Intelligent User Interfaces Companion. Edited by George A. Papadopoulos et al., 89-92. New York N.Y. ACM 2017.

Rodriguez, Leonardo, Fabian Quint, and Dominic Gorecky et al. "Developing a Mixed Reality Assistance System Based on Projection Mapping Technology for Manual Operations at Assembly Workstations." Procedia Computer Science 75 (2015):327-333.

Sand, Oliver, Sebastian Büttner, and Volker Paelke et al. "smARt.Assembly - Projection-Based Augmented Reality for Supporting Assembly Workers." In Proceedings of the Virtual, Augmented and Mixed Reality: 8th International Conference. Vol. 9740. Edited by Stephanie Lackey and Randall Shumaker, 643-52 2016.

Sanna, A., F. Manuri, and F. Lamberti et al. "Using handheld devices to sup port augmented realitybased maintenance and assembly tasks." In IEEE International Conference on Consumer Electronics (ICCE), 2015: 9 - 12 Jan. 2015, Las Vegas, NV, USA, 178-179. Piscataway, NJ. IEEE 2015.

Sarupuri, Bhuvaneswari, Gun A. Lee, and Mark Billinghurst. "Using augmented reality to assist forklift operation." In Proceedings of the 28th Australian Conference on Computer-Human Interaction. Edited by Henry Duh et al., 16-24 2016.

Sauer, Steffen, Drik Berndt, and Jost Schnee et al. "Worker Assistance and Quality Inspection: Application of Optical 3D Metrology and Augmented Reality Technologies." In 14th Joint International IMEKO TC1, TC7, TC13 Symposium on Intelligent Quality Measurements - Theory, 112-13. Red Hook, N.Y. Printed by Curran Associates 2011.

Saunders, Mark, Philip Lewis, and Adrian Thornhill. Research methods for business student: fifth Edition. 5 vols. Harlow: Pearson Education, 2009.

Saxen, Frerk, Anne Köpsel, and Simon Adler et al. "Investigation of an Augmented Reality-based Machine Operator Assistance-System." In Companion technology: A paradigm shift in human-technology interaction. Edited by Susanne Biundo and Andreas Wendemuth, 471-483. Cognitive technologies. Cham, Switzerland. Springer 2017.

Schlagowski, R., L. Merkel, and C. Meitinger. "Design of an assistant system for industrial maintenance tasks and implementation of a prototype using augmented reality." In 2017 IEEE International Conference on Industrial Engineering \& Engineering Management: IEEE IEEM2017 10-13 Dec, Singapore, 294-298. Piscataway, NJ. IEEE 2017.

Scupola, Ada. "The Adoption of Internet Commerce by SMEs in the South of Italy: An Environmental, Technological and Organizational Perspective." Journal of Global Information Technology Management 6, 1 (2014):52-71.

Segovia, Daniel, Miguel Mendoza, and Eloy Mendoza et al. "Augmented Reality as a Tool for Production and Quality Monitoring." Procedia Computer Science 75 (2015):291-300.

Segura, Alvaro, Helen V. Diez, Inigo Barandiaran et al. "Visual computing technologies to support the Operator 4.0." Computers \& Industrial Engineering (in press) Accepted for publication on 28 November, 2018, https://doi.org/10.1016/j.cie.2018.11.060.

Seki, Hirosato, Toyokazu Nose, Young Hae Lee et al. "Special issue on recent advances in Intelligent Manufacturing Systems." Computers \& Industrial Engineering 65, 1 (2013):1.

Serrano, Veronica, and Thomas Fischer. "Collaborative innovation in ubiquitous systems." Journal of Intelligent Manufacturing 18, 5 (2007):599-615.

Serván, J., F. Mas, and J. L. Menéndez et al. "Assembly Work Instruction Deployment Using Augmented Reality." Key Engineering Materials 502 (2012):25-30.

Smith, Shana, Gregory C. Smith, and Roger Jiao et al. "Mass customization in the product life cycle." Journal of Intelligent Manufacturing 24, 5 (2013):877-85.

Soete, N., A. Claeys, and S. Hoedt et al. "Towards Mixed Reality in SCADA Applications." IFAC-PapersOnLine 48, 3 (2015):2417-22.

Stoltz, Marie-Hélène, Vaggelis Giannikas, and Duncan McFarlane et al. "Augmented Reality in Warehouse Operations: Opportunities and Barriers." IFACPapersOnLine 50, 1 (2017):12979-12984.

Sutherland, Ivan E. "A head-mounted three dimensional display." In Proceedings of the December 9-11, 1968, fall joint computer conference, part I on - AFIPS '68 (Fall, part I). Edited by Unknown, 757-764. New York, New York, USA. ACM Press 1968.

Syberfeldt, Anna, Magnus Holm, and Oscar Danielsson et al. "Support Systems on the Industrial Shop-floors of the Future - Operators' Perspective on Augmented Reality." Procedia CIRP 44 (2016):108-13.

Tompkins, James A. Facilities planning. 4th ed. Hoboken, NJ: Wiley, 2010. http://www.loc.gov/catdir/enhancements/fy1011/2 010455781-d.html. 
Tong, Yanfeng, Yongtian Wang, and Jing Chen et al. "A small scene assistant maintenance system based on optical see-through augmented reality." In the 15th ACM SIGGRAPH Conference. Edited by Yiyu Cai and Daniel Thalmann, 155-158 2016.

Trappey, Amy J.C., Charles V. Trappey, and Usharani Hareesh Govindarajan et al. "A review of essential standards and patent landscapes for the Internet of Things: A key enabler for Industry 4.0." Advanced Engineering Informatics 33 (2017):208-229.

Uva, Antonio E., Michele Gattullo, and Vito M. Manghisi et al. "Evaluating the effectiveness of spatial augmented reality in smart manufacturing: A solution for manual working stations." The International Journal of Advanced Manufacturing Technology 94, 14 (2018):509-521.

Wang, Junfeng, Yaqing Feng, and Cheng Zeng et al. "An augmented reality based system for remote collaborative maintenance instruction of complex products." In IEEE International Conference on Automation Science and Engineering (CASE), 2014: 18 - 22 Aug. 2014, Taipei, Taiwan, 309-14. Piscataway, NJ. IEEE 2014.

Wang, X., and Phillip S. Dunston. "A User-centered Taxonomy for Specifying Mixed Reality Systems for AEC Industry." Journal of Information Technology in Constrution, 16 (2011):493-508.

Wang, X., S. K. Ong, and A. Y. C. Nee. "A comprehensive survey of augmented reality assembly research." Advances in Manufacturing 4, 1 (2016):1-22.

Wang, X., S. K. Ong, and A.Y.C. Nee. "Multi-modal augmented-reality assembly guidance based on barehand interface." Advanced Engineering Informatics 30, 3 (2016):406-421.

Wang, Yue, Shusheng Zhang, and Sen Yang et al. "Mechanical assembly assistance using marker-less augmented reality system." Assembly Automation 38, 1 (2018):77-87.

Wang, Yu-Min, Yi-Shun Wang, and Yong-Fu Yang. "Understanding the determinants of RFID adoption in the manufacturing industry." Technological Forecasting and Social Change 77, 5 (2010):803-815.

Werrlich, Stefan, Kai Nitsche, and Gunther Notni. "Demand Analysis for an Augmented Reality based Assembly Training." In Proceedings of the 10th International Conference on Pervasive Technologies Related to Assistive Environments, 416-422. New York, NY. ACM 2017.

Wilding, Richard, Claudia Colicchia, and Fernanda Strozzi. "Supply chain risk management: A new methodology for a systematic literature review." Supply Chain Management: An International Journal 17, 4 (2012):403-18.

Wójcicki, Tomasz. "Supportin the Diagnostics and the Maintenance of Technical Devices with Augmented Reality." Diagnostyka 1, 15 (2014):43.

Wolfartsberger, Josef, Jan Zenisek, and Mathias Silmbroth et al. "Towards an Augmented Reality and SensorBased Assistive System for Assembly Tasks." In
Proceedings of the 10th International Conference on Pervasive Technologies Related to Assistive Environments, 230-231. New York, NY. ACM 2017.

Wu, Changliang, and Heng Wang. "A Multi-Modal Augmented Reality Based Virtual Assembly System." In Proceedings of the International Conference on Human-centric Computing 2011 and Embedded and Multimedia Computing 2011. Vol. 102. Edited by Jame J. Park et al., 65-72. Lecture Notes in Electrical Engineering. Dordrecht. Springer Netherlands 2011.

$\mathrm{Wu}$, Li-Chen, I-Chen Lin, and Ming-Han Tsai. "Augmented reality instruction for object assembly based on markerless tracking." In Proceedings of the 20th ACM SIGGRAPH Symposium. Edited by Chris Wyman and Cem Yuksel, 95-102 2016.

$\mathrm{Xu}$, Li Da, and Lian Duan. "Big data for cyber physical systems in industry 4.0: A survey." Enterprise Information Systems 35, 1 (2018):1-22.

$\mathrm{Xu}$, Li Da, Wu He, and Shancang Li. "Internet of Things in Industries: A Survey." IEEE Transactions on Industrial Informatics 10, 4 (2014):2233-43.

Yan, Jihong, Yue Meng, and Lei Lu et al. "Industrial Big Data in an Industry 4.0 Environment: Challenges, Schemes, and Applications for Predictive Maintenance." IEEE Access 5 (2017):23484-91.

Yao, Xifan, Jiajun Zhou, and Yingzi Lin et al. "Smart manufacturing based on cyber-physical systems and beyond." Journal of Intelligent Manufacturing 10, 1 (2017):175.

Yew, A.W.W., S. K. Ong, and A.Y.C. Nee. "Towards a griddable distributed manufacturing system with augmented reality interfaces." Robotics and Computer-Integrated Manufacturing 39 (2016):4355.

Zhang, Yingfeng, Geng Zhang, and Yang Liu et al. "Research on services encapsulation and virtualization access model of machine for cloud manufacturing." Journal of Intelligent Manufacturing 28, 5 (2017):1109-23.

Zhou, Jianlong, Ivan Lee, and Bruce Thomas et al. "Applying spatial augmented reality to facilitate insitu support for automotive spot welding inspection." In Proceedings of the 10th International Conference on Virtual Reality Continuum and Its Applications in Industry. Edited by Zhi-Qiang Liu, 195. New York, NY. ACM 2011.

Zhou, Ying, Hanbin Luo, and Yiheng Yang. "Implementation of augmented reality for segment displacement inspection during tunneling construction." Automation in Construction 82 (2017):112-21.

Zhou, ZhiYing, Adrian David Cheok, and Yan Qiu et al. "The Role of 3-D Sound in Human Reaction and Performance in Augmented Reality Environments." IEEE Transactions on Systems, Man, and Cybernetics Part A: Systems and Humans 37, 2 (2007):262-272.

Zhu, J., S. K. Ong, and A. Y. C. Nee. "An authorable contextaware augmented reality system to assist the maintenance technicians." The International Journal 
of Advanced Manufacturing Technology 45 (2012):1699-1714.

Zhu, Yan, Yan Li, and Weiquan Wang et al. "What leads to post-implementation success of ERP? An empirical study of the Chinese retail industry." International Journal of Information Management 30, 3 (2010):265276. 